Please do not remove this page

RMIT

UNIVERSITY

\title{
The efficiency of ultra-high molecular weight polyethylene composite against fragment impact
}

Nguyen, Long; Ryan, Shannon; Cimpoeru, Stephen; Mouritz, Adrian; Orifici, Adrian

https://researchrepository.rmit.edu.au/esploro/outputs/9921860201801341/filesAndLinks?institution=61RMIT_INST\&index=null

Nguyen, L., Ryan, S., Cimpoeru, S., Mouritz, A., \& Orifici, A. (2016). The efficiency of ultra-high molecular weight polyethylene composite against fragment impact. Experimental Mechanics, 56(4), 595-605.

https://doi.org/10.1007/s11340-015-0051-z

Document Version: Accepted Manuscript

Published Version: https://doi.org/10.1007/s11340-015-0051-z

Repository homepage: https://researchrepository.rmit.edu.au

(C) 2015 Society for Experimental Mechanics

Downloaded On 2023/04/26 15:59:56 +1000 
Thank you for downloading this document from the RMIT Research Repository.

The RMIT Research Repository is an open access database showcasing the research outputs of RMIT University researchers.

RMIT Research Repository: http://researchbank.rmit.edu.au/

\section{Citation:}

Nguyen, L, Ryan, S, Cimpoeru, S, Mouritz, A and Orifici, A 2015, 'The efficiency of ultra-high molecular weight polyethylene composite against fragment impact', Experimental Mechanics, pp. 1-11.

See this record in the RMIT Research Repository at:

https://researchbank.rmit.edu.au/view/rmit:34175

Version: Accepted Manuscript

Copyright Statement: (c) 2015 Society for Experimental Mechanics

Link to Published Version:

http://dx.doi.org/10.1007/s11340-015-0051-z 


\section{Experimental Mechanics}

\section{The efficiency of ultra-high molecular weight polyethylene composite against fragment impact \\ --Manuscript Draft--}

\begin{tabular}{|c|c|}
\hline \multicolumn{2}{|l|}{ Manuscript Number: } \\
\hline Keywords: & $\begin{array}{l}\text { UHMW polyethylene; ballistic impact; composite armour; mass efficiency, space } \\
\text { efficiency }\end{array}$ \\
\hline \multicolumn{2}{|l|}{$\begin{array}{l}\text { Corresponding Author Secondary } \\
\text { Information: }\end{array}$} \\
\hline First Author: & Long Hoang Nguyen \\
\hline \multicolumn{2}{|l|}{ First Author Secondary Information: } \\
\hline \multirow[t]{5}{*}{ Order of Authors: } & Long Hoang Nguyen \\
\hline & Shannon Ryan \\
\hline & Stephen J Cimpoeru \\
\hline & Adrian P Mouritz \\
\hline & Adrian C Orifici \\
\hline
\end{tabular}

\section{Additional Information:}

\section{Question}

Please suggest up to three (3) possible reviewers's names and email addresses for your manuscript. If you do not want to suggest reviewers, you need to enter the text: "Reviewers are not being suggested." Because this is a required

\section{Response}

Reviewers are not being suggested 
field text box, typed text must be entered into it in order to build and submit your manuscript. Thank you. 


\title{
The efficiency of ultra-high molecular weight polyethylene composite against
}

\section{fragment impact}

\author{
L.H. Nguyen ${ }^{1,3}$, S. Ryan ${ }^{2,3}$, S.J. Cimpoeru ${ }^{2}$, A.P. Mouritz ${ }^{1}$, A.C. Orifici ${ }^{1}$ \\ ${ }^{1}$ School of Aerospace, Mechanical and Manufacturing Engineering, RMIT University, GPO Box 2476 Melbourne, Australia \\ ${ }^{2}$ Defence Science and Technology Organisation, 506 Lorimer St, Fishermans Bend, Victoria 3207, Australia \\ ${ }^{3}$ Defence Materials Technology Centre, 24 Wakefield St, Hawthorn, Victoria 3122, Australia
}

\begin{abstract}
This paper presents an experimental investigation into the ballistic resistance of ultra-high molecular weight polyethylene (UHMW-PE) composite, and compares its performance against a range of common metallic and composite armour materials. An extensive experimental program was conducted to determine the ballistic limit velocity $\left(\mathrm{V}_{50}\right)$ of UHMW-PE composite against $12.7 \mathrm{~mm}$ and $20 \mathrm{~mm}$ fragment simulating projectiles (FSP) for a wide range of thicknesses. For protection against these projectiles, UHMW-PE composite was found to be consistently more mass efficient than rolled homogeneous armour steel, high hardness armour steel, aluminium alloy 5059-H131, and polymer composites reinforced with aramid, glass or carbon fibres. In terms of armour space claim, UHMW-PE composite was found to be less efficient than both steel types and glass fibre-reinforced plastic, though was comparable to aramid fibre-reinforced plastic, and was more efficient than aluminium 5059-H131 and carbon fibre-reinforced plastic. Scaling effects were observed that showed metals were more effective against smaller projectiles in terms of armour mass required to stop a given projectile kinetic energy. These effects were not observed to the same extent for UHMW-PE composite, giving rise to higher mass efficiency against larger projectiles.
\end{abstract}

Keywords: UHMW polyethylene; ballistic impact; composite armour; mass efficiency, space efficiency 


\section{Introduction}

Fibre-reinforced composites such as ultra-high molecular weight polyethylene (UHMW-PE) composite have been shown to provide highly efficient ballistic protection against small calibre fragments [1, 2], projectiles [3], and spheres [4, 5]. For this reason, they have been widely adopted for weight-critical applications such as personal protection (i.e helmets and vests). Owning to their high strength and low weight it is expected that UHMW-PE composite could provide equally high ballistic protection relative to the weight against large calibre, high lethality threats for vehicle protection where thicker sections could be used.

The penetration and failure mechanism of thick UHMW-PE composite against large calibre fragment threats was investigated in $[6,7]$. As opposed to thin targets that undergo a single stage of perforation through membrane tension [8], these studies showed thick UHMW-PE composite exhibits two distinct stages of penetration: a localised shear plugging phase followed by bulging of the back face and membrane tension. Fractographic analysis of impacted UHMW-PE composite targets showed evidence of delamination, ply splitting and fibre kinking [6] while fibre compression and shear failure on the target front face and tension on the rear were characterised at the penetration cavity [7]. The ballistic performance of UHMW-PE composite was briefly compared against other fibre-reinforced composites in Nguyen et al. [7], however their efficiency as an armour material was not evaluated. Efficiency, in this instance, is assessed in terms of the mass per unit area of an armour system required to protect against a certain threat, relative to the mass of a traditional armour material such as rolled homogeneous armour steel (RHA) required to provide the same level of protection. Mass efficiency is defined as:

$$
E_{m}=\frac{t_{r e f} \times \rho_{r e f}}{t \times \rho}
$$

where $t$ is the armour thickness required to defeat the threat, $\rho$ is the density of the armour material, and the subscript ref refers to the reference condition (e.g. RHA). Another measure of armour efficiency relates to the armour space claim, or the thickness of an armour system required to protect 
against a certain threat, relative to the thickness of a traditional armour material required to provide the same level of protection. Space efficiency is defined as:

$$
E_{s}=\frac{t_{r e f}}{t}
$$

A space and/or mass efficiency value greater than 1.0 indicates a thinner and/or lighter armour than the reference configuration against the same threat. These efficiency factors have been used to evaluate the effectiveness of a range of armour materials including aluminium [9] and ceramics [10, 11], but have not been investigated for UHMW-PE composite nor any other fibre-reinforced composite to the authors' knowledge. Not only are the efficiency factors important for armour design considerations, a deeper understanding of the material properties and the penetration mechanisms that give rise to the ballistic efficiency is critical for further improvements in the armour material.

In this paper the performance of UHMW-PE composite is investigated against large calibre $(12.7 \mathrm{~mm}$ and $20 \mathrm{~mm}$ ) fragment simulating projectiles (FSPs). An extensive experimental program was carried out to determine the ballistic limit velocity, $\mathrm{V}_{50}$, for UHMW-PE composite and two steels of different hardness for a wide range of thicknesses. The results were used to assess the ballistic performance of UHMW-PE composite compared to existing fibre-reinforced composite and traditional metallic armour materials in terms of mass and space efficiency. Key penetration mechanisms for the different materials are compared in order to provide grounds for the varying efficiency figures. 


\section{Ballistic testing}

Tests were performed on UHMW-PE composite and steel to determine the ballistic limit velocity against $12.7 \mathrm{~mm}$ and $20 \mathrm{~mm}$ calibre MIL-DTL-46593 [12] fragment simulating projectiles (FSPs) for various thicknesses. The geometry of the two FSPs is shown in Figure 1.

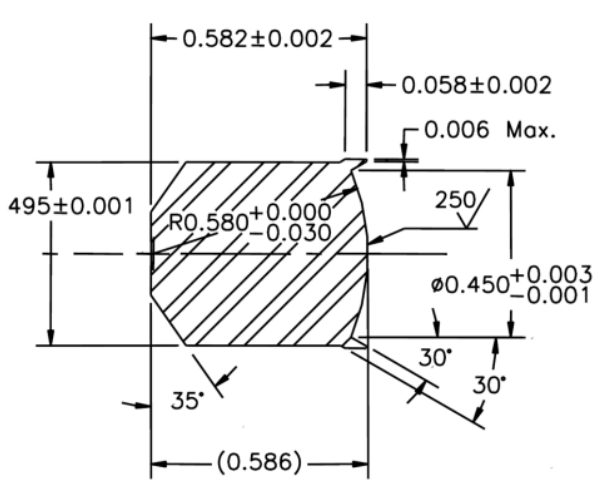

$12.7 \mathrm{~mm}$ FSP

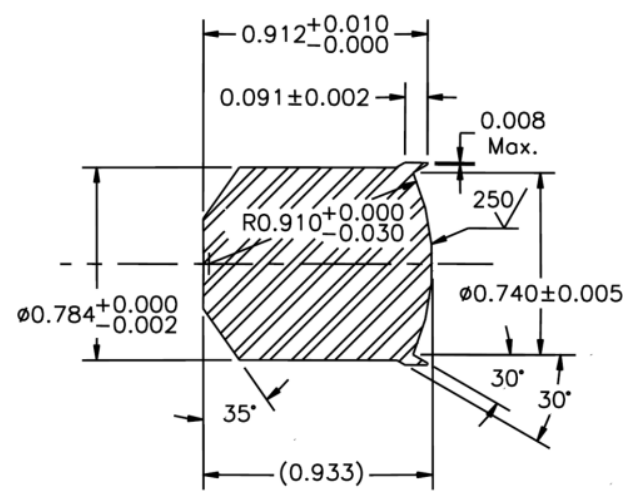

$20 \mathrm{~mm}$ FSP

Figure 1. Geometry of MIL-DTL-46593 fragment simulating projectiles (dimensions in inches) [12]. The projectiles are designed to be scaled versions of the same representative threat. As such, common ballistic characteristics such as length-todiameter ratio, $\mathrm{L} / \mathrm{D}$, are nominally identical for the $12.7 \mathrm{~mm}$ and $20 \mathrm{~mm}$ calibres.

Testing was conducted using a range of facilities according to the projectile calibre and required impact velocity:

- For the lower impact velocities, typically less than $1000 \mathrm{~m} / \mathrm{s}$, tests were performed on 12.7 $\mathrm{mm}$ and $20 \mathrm{~mm}$ barrels mounted to a universal receiver. Velocity measurements were made via two laser break screens.

- For intermediate velocities, tests were performed using $12.7 \mathrm{~mm}$ and $20 \mathrm{~mm}$ diameter barrels with a powder breech. Velocity measurements were made via optical chronograph;

- For the highest velocities, tests were performed using $20 \mathrm{~mm}$ and $30 \mathrm{~mm}$ diameter barrels with a powder breech, in which the sub-calibre FSPs were saboted. For these tests flatbacked variants of the FSPs were used. Velocity measurements were made via dual lightsensing skyscreens and confirmed via radar measurement. 
The $\mathrm{V}_{50}$ ballistic limit of the target panels was assessed in accordance with MIL-STD-662 [13], corresponding to the impact velocity at which the panel will be perforated with a $50^{\text {th }}$ percentile probability.

\section{$2.1 \quad$ UHMW-PE Composite}

Ballistic testing was performed on Dyneema ${ }^{\circledR}$ HB26, a unidirectional composite produced by DSM. The composite consists of approximately $80 \%$ fibre volume fraction of Dyneema ${ }^{\circledR}$ SK76 fibres in a polyurethane matrix. The plies are approximately $60 \mu \mathrm{m}$ thick, are laid in a $[0 / 90]_{\mathrm{n}}$ stacking sequence and hot pressed under $125^{\circ} \mathrm{C}$ and $14 \mathrm{MPa}$ of pressure to fuse them together into a monolithic composite panel. Target thicknesses between $10 \mathrm{~mm}$ to $100 \mathrm{~mm}$ were tested. Not all $75 \mathrm{~mm}$ and 100 mm thick UHMW-PE monolithic panels could be sourced, so additional panels of these thicknesses were produced through a secondary consolidation process using thinner panels $(25 \mathrm{~mm}$ and $50 \mathrm{~mm})$ at $0.9 \mathrm{MPa}$ and $125^{\circ} \mathrm{C}$. Comparison between monolithic panels and those produced through the secondary consolidation process showed no discernible performance difference, although the panels typically separated along these new consolidated planes under impact.

The panels typically had lateral dimensions of $300 \mathrm{~mm} \times 300 \mathrm{~mm}$, except for the $75 \mathrm{~mm}$ and $100 \mathrm{~mm}$ thick targets which were $400 \mathrm{~mm} \times 400 \mathrm{~mm}$. No witness plate was used for the UHMW-PE tests; rather complete penetration $(\mathrm{CP})$ was defined by perforation of the rearmost ply of the composite panel. Test on panels $25 \mathrm{~mm}$ thick or less were initially performed with the panels bolted between two $8 \mathrm{~mm}$ thick steel plates with four $100 \mathrm{~mm}$ diameter apertures. This was for economy of target materials, allowing four tests to be performed on the one target. To ensure the $\mathrm{V}_{50}$ results were not influenced by the additional confinement of the steel plates, verifications tests were performed with a single shot on a full panel. Results on the confined targets were within the experimental scatter range of the single shot verification tests, consistent with findings from Lee et al. [2]. Targets thicker than $25 \mathrm{~mm}$ were not testing using the aperture confinement as excessive drawing of material was expected to influence the result. 


\subsection{Armour steel}

Ballistic tests were performed on two armour steels to provide a baseline for performance comparison. The two steels were BISPLATE® High Hardness Armour (HHA) plate, a nom. 500 HB steel conforming to MIL-DTL-46100 [14], and BISPLATE® High Impact Armour plate (Class 1), a nom. 350 HB steel corresponding to a Class 1 armour plate as per MIL-A-12560 [15]. High Impact Armour is considered analogous to rolled homogenous armour (RHA), and will be referred to herein as RHA steel.

For testing on the steel targets the complete penetration (CP) threshold was defined by light transmission through $0.1 \mathrm{~mm}$ thick Al 5005-H34 witness plates spaced $100 \mathrm{~mm}$ from the rear face of the target plate.

\section{Results}

The ballistic limit test results are shown in Table 1 . All calculated $V_{50}$ values conform to MIL-STD662 [13] except the $50 \mathrm{~mm}$ thick Dyneema ${ }^{\circledR}$ HB26 against the $12.7 \mathrm{~mm}$ FSP, which only used one partial penetration and one complete penetration result to determine the $\mathrm{V}_{50}$.

Table 1. Overview of ballistic test results.

\begin{tabular}{ccccc}
\hline Material & Thickness $(\mathrm{mm})$ & Projectile & $\mathrm{V}_{50}(\mathrm{~m} / \mathrm{s})$ & $\sigma(\mathrm{m} / \mathrm{s})$ \\
\hline Dyneema ${ }^{\circledR}$ HB26 & 9.1 & $12.7 \mathrm{~mm}$ FSP & 506 & 26.4 \\
Dyneema ${ }^{\circledR}$ HB26 & 20 & $12.7 \mathrm{~mm}$ FSP & 825.8 & 17.2 \\
Dyneema ${ }^{\circledR}$ HB26 & 25.2 & $12.7 \mathrm{~mm}$ FSP & 1021.4 & 8.5 \\
Dyneema ${ }^{\circledR}$ HB26 & 35.1 & $12.7 \mathrm{~mm}$ FSP & 1250.3 & 36.1 \\
Dyneema ${ }^{\circledR}$ HB26 & 50.4 & $12.7 \mathrm{~mm}$ FSP & $1656.5^{*}$ & 16.3 \\
Dyneema ${ }^{\circledR}$ HB26 & 10 & $20 \mathrm{~mm}$ FSP & 393.9 & 43 \\
Dyneema ${ }^{\circledR}$ HB26 & 20 & $20 \mathrm{~mm}$ FSP & 620.1 & 19.6 \\
Dyneema ${ }^{\circledR}$ HB26 & 36.2 & $20 \mathrm{~mm}$ FSP & 901.4 & 9.8 \\
Dyneema ${ }^{\circledR}$ HB26 & 75.6 & $20 \mathrm{~mm}$ FSP & 1527.6 & 104.6 \\
Dyneema ${ }^{\circledR}$ HB26 & 101.7 & $20 \mathrm{~mm} \mathrm{FSP}$ & 2001.8 & 91.8 \\
RHA steel & 6.6 & $12.7 \mathrm{~mm}$ FSP & 612.1 & 8.5
\end{tabular}


RHA steel

RHA steel

HHA steel

HHA steel

"Calculated from a single PP and CP result, does not meet the minimum requirement of MIL-STD-662 [13]

\section{Target Effectiveness}

\subsection{Comparison with metal}

Figure 2 plots the ballistic test results of Dyneema ${ }^{\circledR}$ HB26, RHA steel and HHA steel in terms of a non-dimensionalised ratio of target areal density $A D_{t}$, multiplied by projectile presented area $A_{p} A_{p}$, divided by the projectile mass, $m_{p}$ with additional data for HHA and RHA steels taken from [16-18]. Data on aluminium alloy 5059-H131 from [19] is also included in the plot. The UHMW-PE composite data is shown to collapse upon a single curve. Similarly, there is no apparent difference between the Al 5059-H131 results with 12.7 mm FSPs and 20 mm FSPs. Both RHA and HHA show some scatter between the results. On a mass basis, UHMW-PE composite is shown to have significantly higher ballistic performance compared to the other materials for this class of projectile.

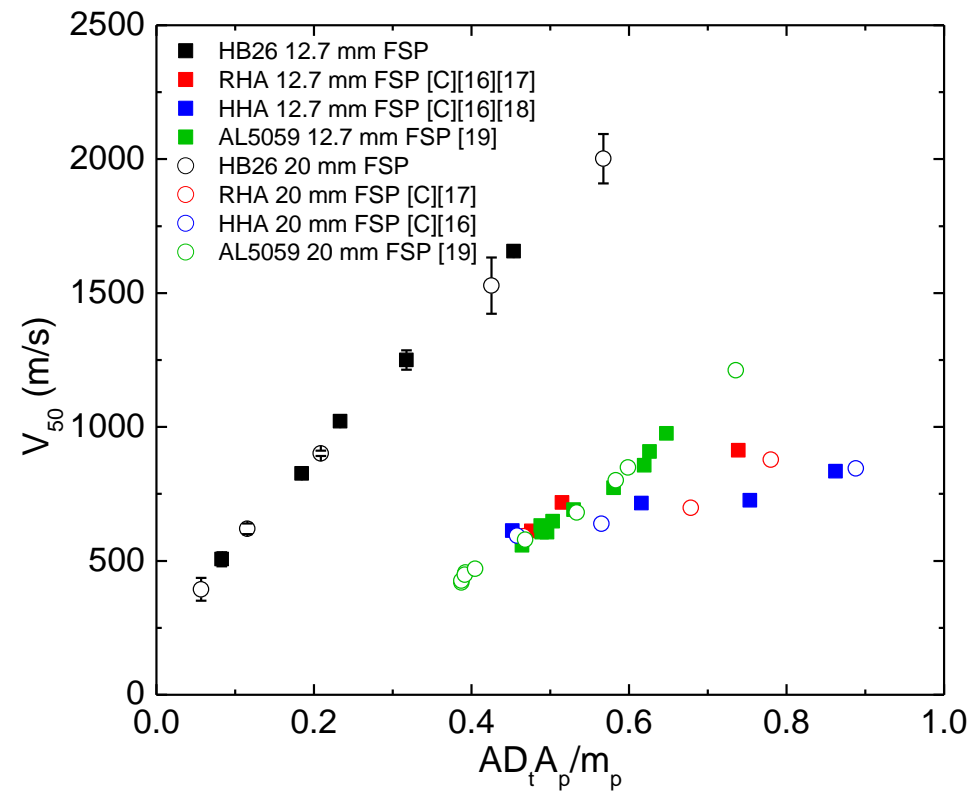


Figure 2. Ballistic limit of UHMW-PE composite for $12.7 \mathrm{~mm}$ and $20 \mathrm{~mm}$ calibre fragment simulating projectiles, compared to RHA, HHA, and $\mathrm{Al}$ 5059-H131 in terms of non-dimensional areal density. [C] for current study.

The mass efficiency of UHMW-PE is plotted in Figure 3 for the $12.7 \mathrm{~mm}$ and $20 \mathrm{~mm}$ FSP against that of HHA steel and Al 5059-H131, with RHA steel as the reference material. Although only limited results are presented for RHA steel, they are consistent with data from additional sources (e.g. [20]). A validated analytical model developed by Nguyen et al. [7] was used to extrapolate the UHMW-PE results to higher areal densities. For both the $12.7 \mathrm{~mm}$ and $20 \mathrm{~mm}$ FSP, the mass efficiency of Dyneema ${ }^{\circledR}$ HB26 is much higher than HHA steel and aluminium alloy for the range of target areal densities investigated. The mass efficiency is shown to approach approximately 4.5 for very thin panels with both projectile calibres. As the areal density is increased, the mass efficiency is shown to initially decrease until panel areal densities of approximately $50 \mathrm{~kg} / \mathrm{m}^{2}$, above which the mass efficiency is seen to asymptote at 3.0 for the $12.7 \mathrm{~mm}$ FSP and 3.8 for the $20 \mathrm{~mm}$ FSP.
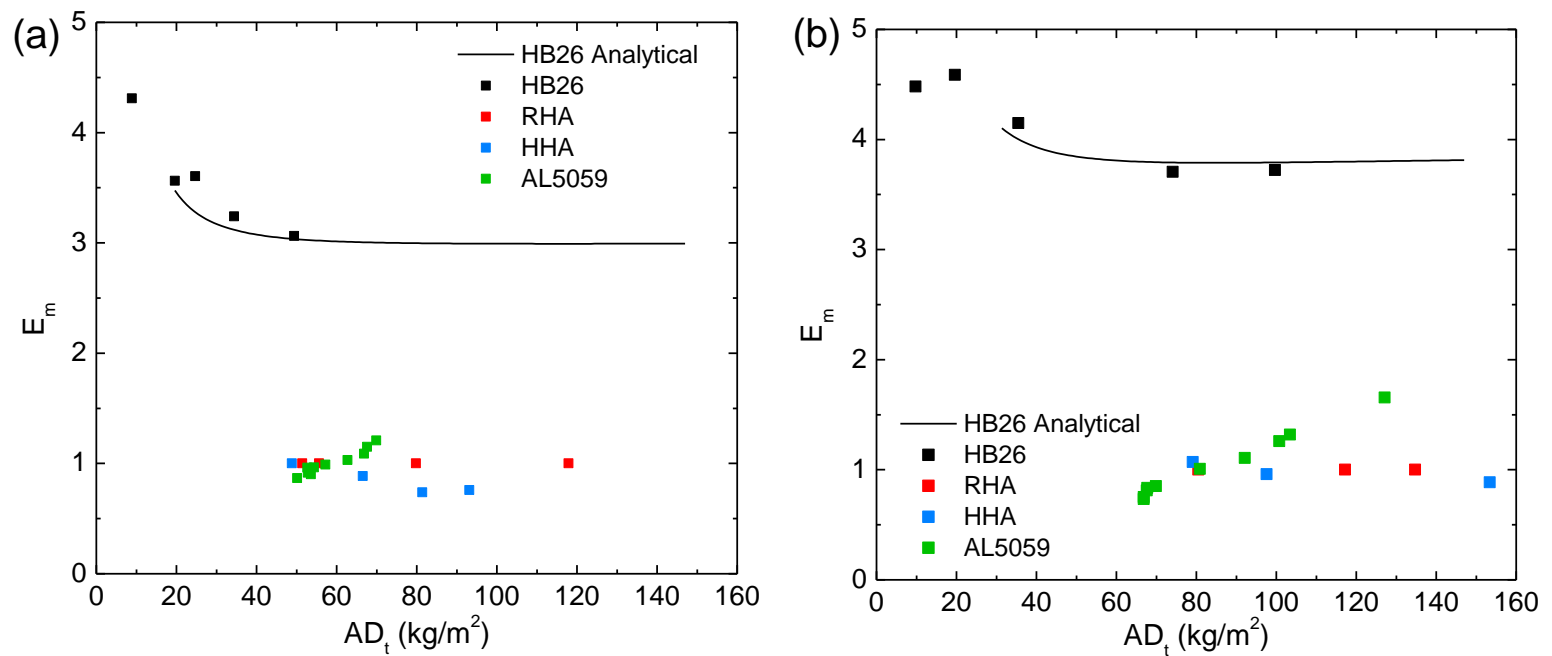

Figure 3. Mass efficiency of targets against (a) $12.7 \mathrm{~mm}$ FSP and (b) $20 \mathrm{~mm}$ FSP in terms of target areal density.

The resistance to penetration of thin UHMW-PE composite is dominated by membrane stresses when impacted at velocities close to the ballistic limit [7]. As the target thickness decreases, the membrane response becomes increasingly efficient due to decreasing transverse constraint provided by adjacent plies [21]. For thicker UHMW-PE panels, penetration occurs in two stages: an initial shear plugging phase followed by the aforementioned membrane tension phase. Figure 4 shows scanning electron microscope images of the fractured fibres at the penetration cavity of a $35 \mathrm{~mm}$ thick target impacted 
by a $12.7 \mathrm{~mm}$ FSP just above the ballistic limit velocity. Figure 4 (a) and Figure 4 (b) show fibres in the shear plugging stage, exhibiting lateral compression and fibre shearing failure whereas Figure 4 (c) and Figure 4 (d) in the membrane tension stage show fibre elongation and tension failure.

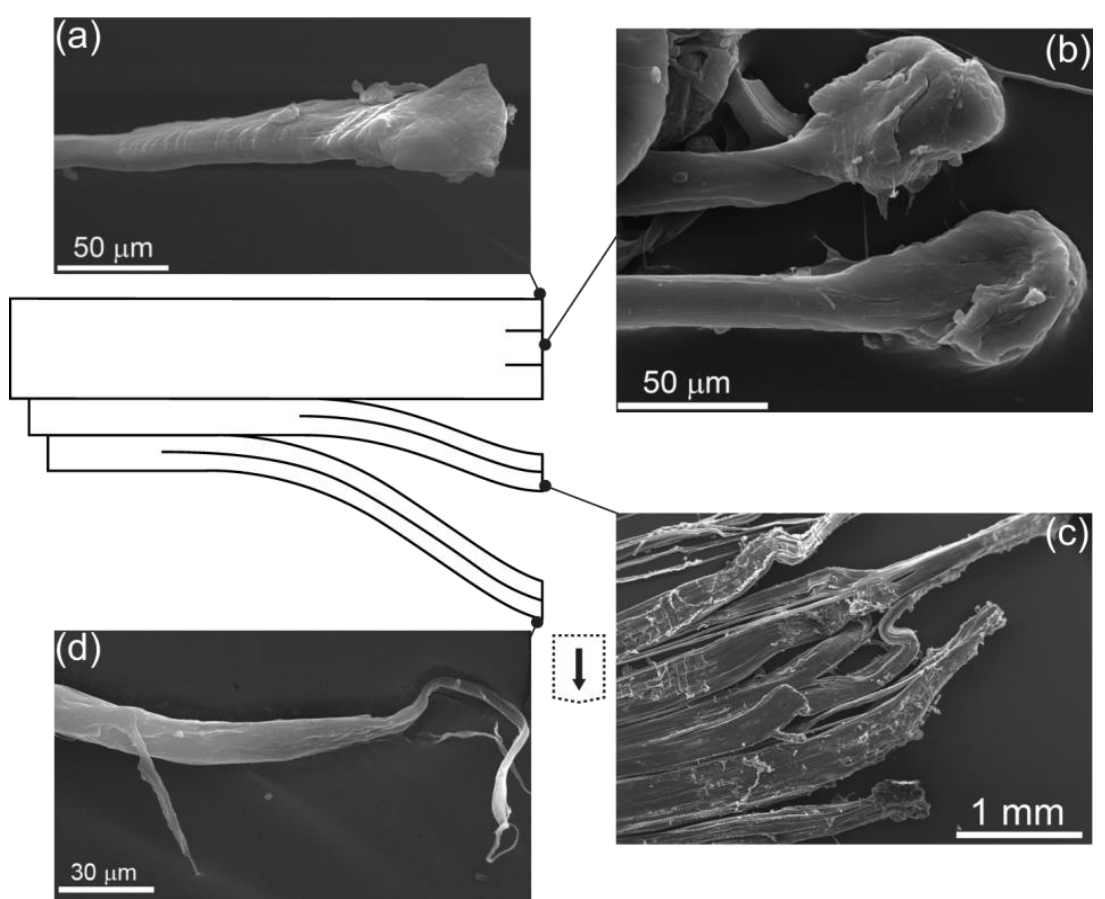

Figure 4. Micrographs of fibre fracture morphology through the penetration cavity of $35 \mathrm{~mm}$ target impacted by $12.7 \mathrm{~mm}$ FSP at (a) target front face, (b) $9 \mathrm{~mm}$ from front face, (c) $18 \mathrm{~mm}$ from front face and (d) target back face [7].

The transition from single- to two-phase perforation was experimentally observed to occur at a nondimensionalised areal density value of about 0.08 for tests close to the ballistic limit [7]. Above this value, the thickness of UHMW-PE composite penetrated in shear plugging is related to the total thickness of the panel by a power law fit, shown in Figure 5. As the ratio of thicknesses between the two penetration phases stabilises, i.e. greater than approximately 0.4 on the non-dimensional areal density axis, the mass efficiency of the UHMW-PE composite is also found to stabilise in Figure 5. This suggests that the membrane tension mechanism is significantly more efficient at protecting against fragment threats on a mass basis than the shear plugging mechanism. 

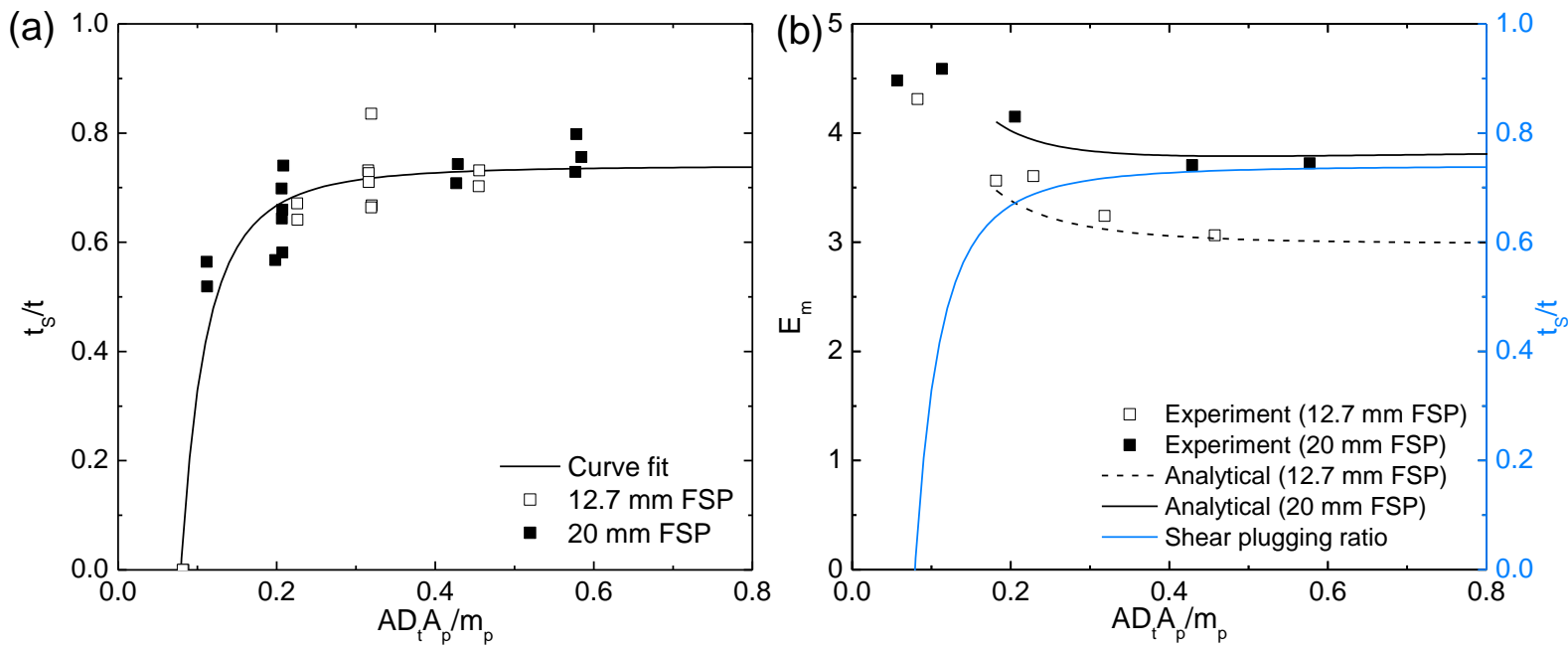

Figure 5. (a) The ratio of UHMW-PE composite panel thickness penetrated in shear plugging, $\mathrm{t}_{\mathrm{s}}$, to the total panel thickness, $\mathrm{t}$, against the non-dimensionalised areal density ratio, fitted to a power law (see [7]). (b) Correlation between the mass efficiency of UHMW-PE composite and the ratio of panel thickness penetrated in shear plugging with respect to the nondimensional areal density ratio.

It is also of interest to note that the efficiency of HHA steel is shown to decrease with increasing areal density against both calibre FSP threats. High hardness steels is widely known to be susceptible to shear plugging, particularly when impacted by blunt nosed projectiles [22-24]. Adiabatic shear plugging is a low energy failure mode, and thus targets perforated in this manner will be less efficient than those perforated in higher energy modes [22]. Gooch et al. [16] showed experimentally that the ballistic performance of a range of steel types against $12.7 \mathrm{~mm}$ FSPs decreases with increasing hardness, which can be directly related to increasing susceptibility to adiabatic shearing.

The space efficiency of UHMW-PE composite is plotted in Figure 6 for the $12.7 \mathrm{~mm}$ and $20 \mathrm{~mm}$ FSP against that of HHA steel and Al 5059-H131, again using RHA steel as the reference material. For both calibre FSPs, the space efficiency of Dyneema ${ }^{\circledR}$ HB26 is between $40-60 \%$ that of RHA steel. The space efficiency of UHMW-PE composite is higher than Al 5059-H131 below areal densities of $65 \mathrm{~kg} / \mathrm{m}^{2}$ for the $12.7 \mathrm{~mm} \mathrm{FSP}$ and $110 \mathrm{~kg} / \mathrm{m}^{2}$ for the $20 \mathrm{~mm}$ FSP. 

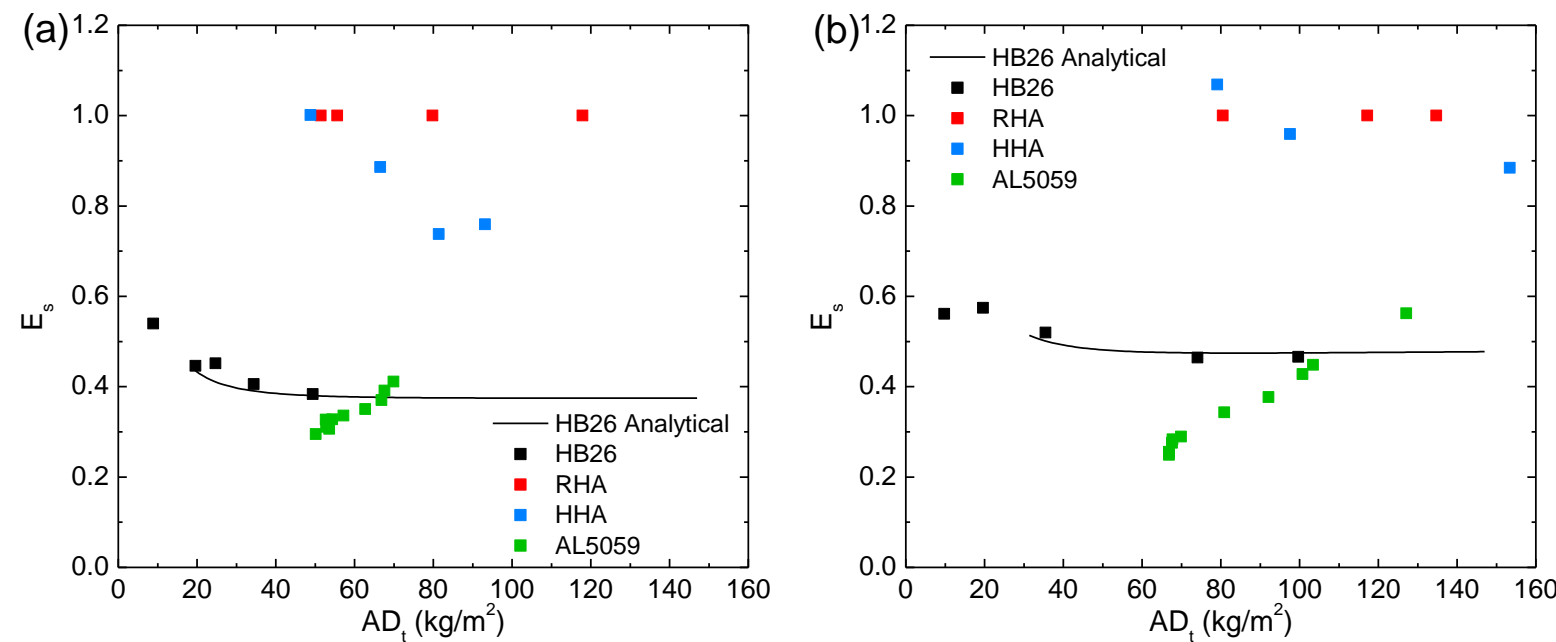

Figure 6. Space efficiency of targets against (a) $12.7 \mathrm{~mm}$ FSP and (b) $20 \mathrm{~mm}$ FSP in terms of target areal density.

The ballistic performance of metals (including armour steels) and ceramics is sensitive to projectile scale, i.e. larger projectiles are more efficient penetrators [25-27]. This is because the level of damage accumulates with respect to absolute time and not scaled time, i.e. small scale projectiles will accumulate less damage than large scale projectiles when impacted at the same velocity for the same time period. Furthermore the strain rates (and therefore strain rate hardening) is higher for sub-scale projectiles compared to full-scale projectiles [26, 27]. In Figure 7 the ballistic limit results of RHA steel and UHMW-PE composite are plotted in terms target areal density and non-dimensionalised areal density ratio for each of the $12.7 \mathrm{~mm}$ and $20 \mathrm{~mm}$ calibre projectiles. The data can be approximated by a linear fit in all instances. When plotted in terms of target areal density there is little to distinguish between the RHA steel and UHMW-PE composite. For both materials the slope of the $20 \mathrm{~mm}$ FSP curve is less than that of the $12.7 \mathrm{~mm}$ curve, as would be expected considering the relative projectile masses. In terms of non-dimensionalised areal density ratio, however, there is a marked difference between the curves for each material. The UHMW-PE composite shows effectively no difference between the two projectile calibres, while for RHA steel the $20 \mathrm{~mm}$ FSP is less effective (i.e. requires less target mass for a given projectile areal density) with increasing areal density ratio. 

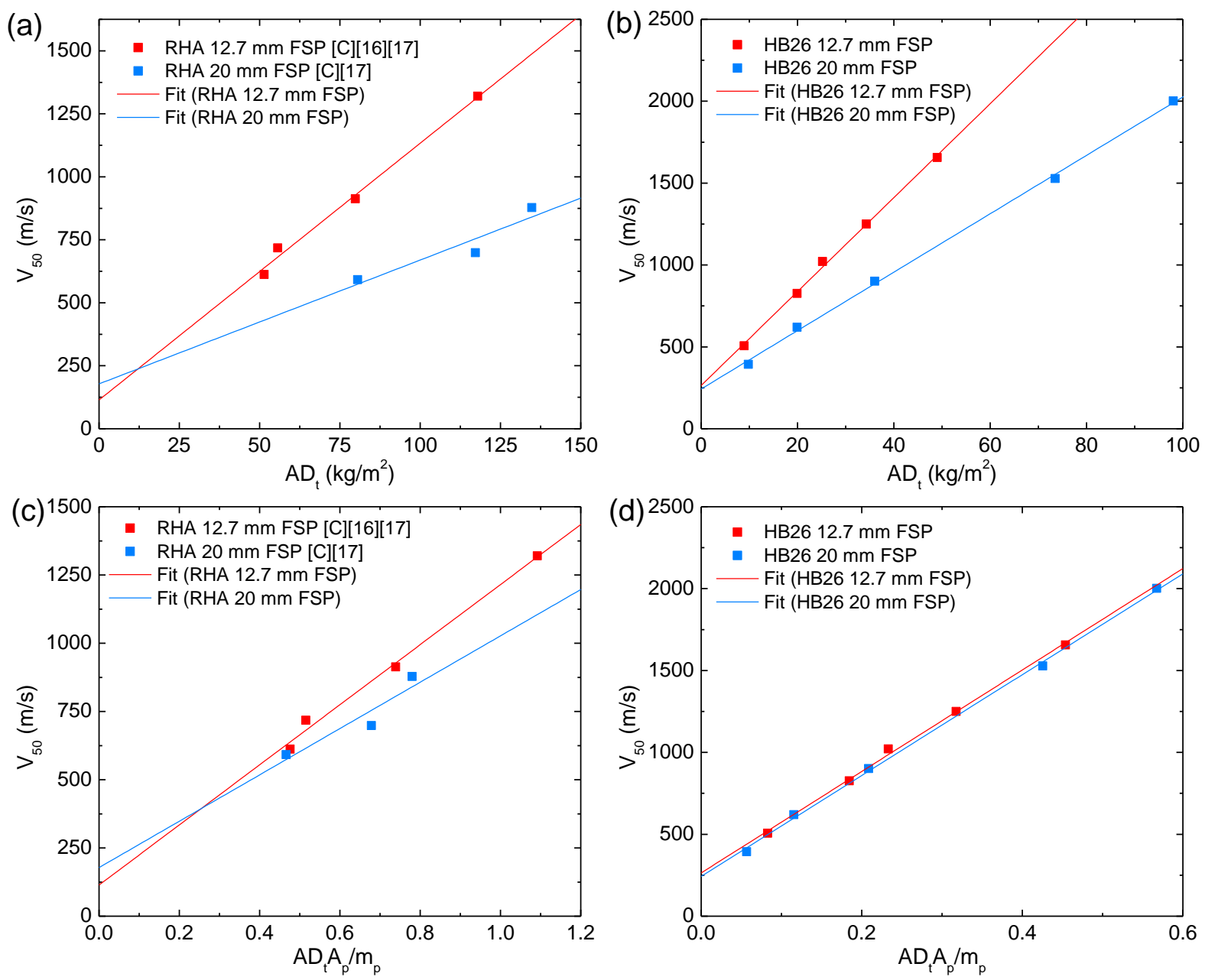

Figure 7. Ballistic limit of RHA and UHMW-PE in terms of target areal density (a) and (b), respectively, and in terms of the non-dimensionalised areal density ratio (c) and (d), respectively. [C] for current study.

The linear trends derived from Figure 7 are plotted in Figure 8 in terms of projectile scale, i.e. projectile diameter normalised by the diameter of the $20 \mathrm{~mm} \mathrm{FSP}, D_{p} / D_{p, 20 \mathrm{~mm} F S P}$ for a range of target thickness to projectile length ratios. The ballistic limit test results are also plotted in Figure 8 . The slopes of the curves are shown to be significantly more pronounced for RHA steel than UHMWPE composite, indicating that the UHMW-PE composite is less sensitive to projectile scale. 

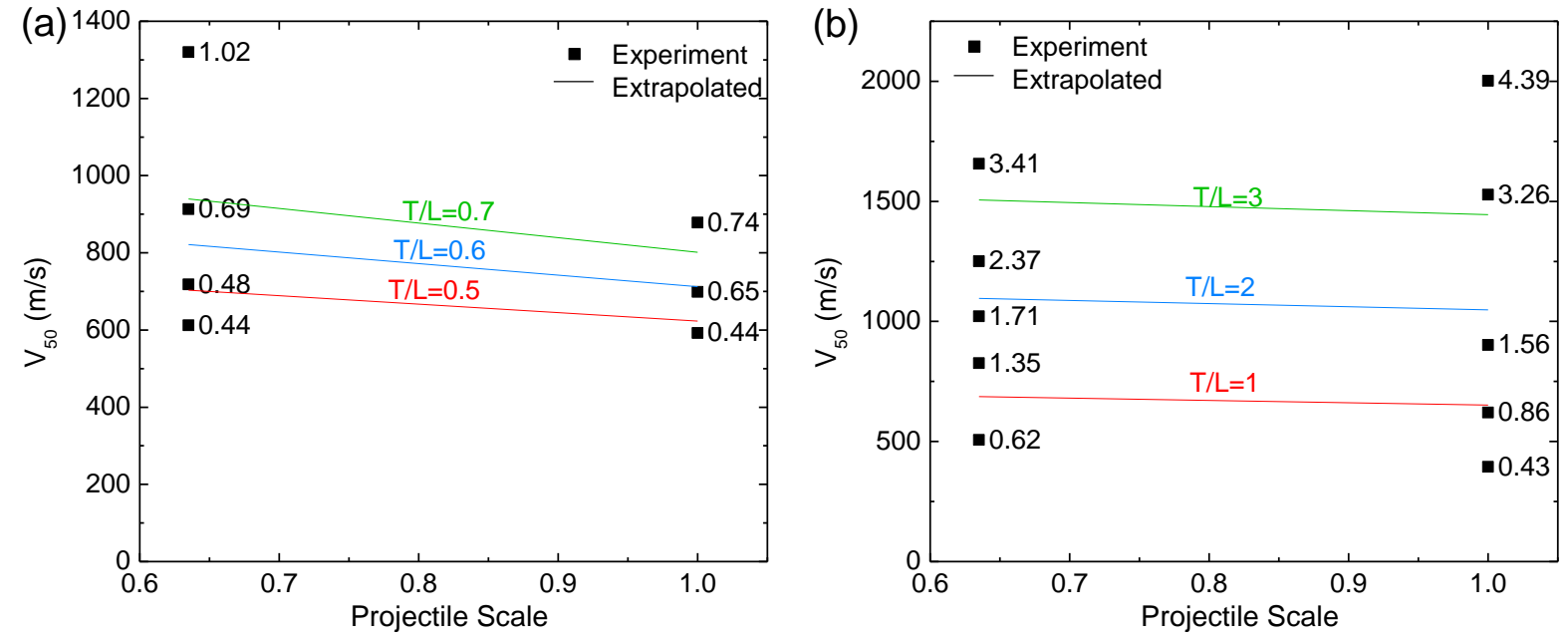

Figure 8. Ballistic limit of (a) RHA and (b) Dyneema HB26 with respect to the projectile scale, where the $20 \mathrm{~mm}$ FSP is the reference projectile.

\subsection{Comparison with fibre-reinforced composites}

Figure 9 compares the $\mathrm{V}_{50}$ of Dyneema ${ }^{\circledR} \mathrm{HB} 26$ with other fibre-reinforced composites in terms of the non-dimensional areal density ratio. Experimental data for Kevlar® KM2/polyvinylbutyral (AFRP), E-glass/polyester (GFRP) and carbon fibre/epoxy (CFRP) were taken from Cunniff [1] where targets were impacted by small calibre $(0.12 \mathrm{~g}$ to $8.2 \mathrm{~g})$ steel and tungsten projectiles with a length-todiameter ratio of approximately 1.0. The UHMW-PE composite is shown to provide higher ballistic performance over the other fibre-reinforced composites for the entire range of areal density values. 


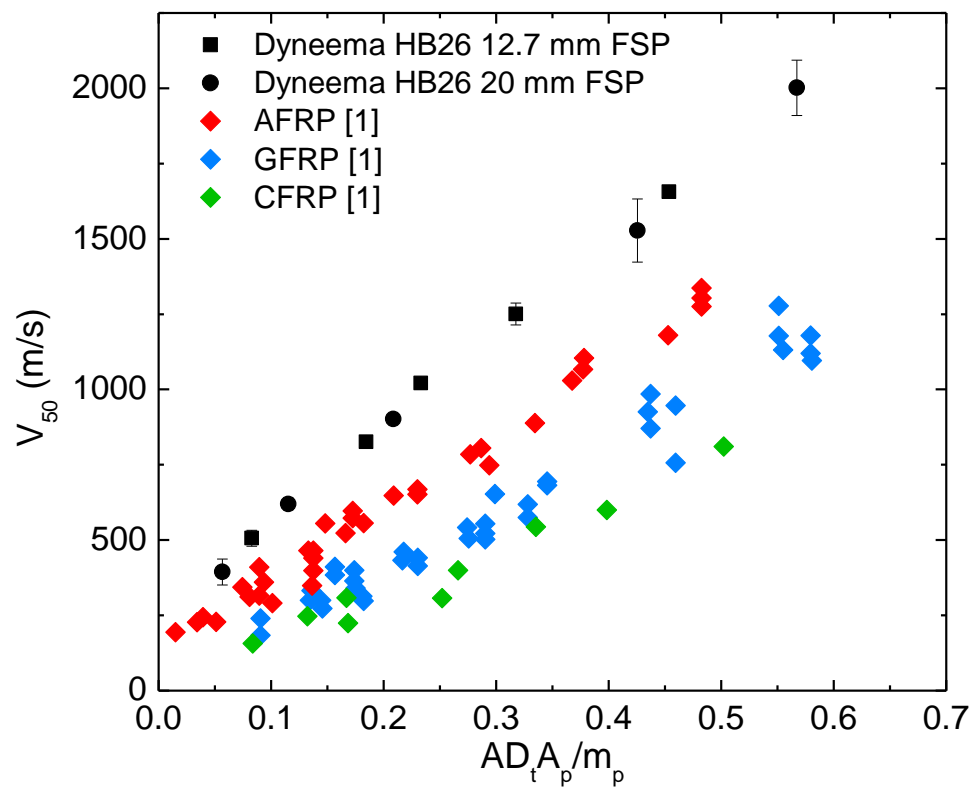

Figure 9. Ballistic limit velocity against non-dimensionalised areal density ratio for various fibre-reinforced composites.

The ballistic performance of fibre-reinforced composites is highly dependent on the mechanical properties of the fibre, namely tensile modulus, strain to failure, tensile strength, and the longitudinal wave speed [1]. A high longitudinal wave speed allows the material to more rapidly distribute the impact load, while a high tensile strength increases the amount of stress the fibre can carry prior to failure. Both the longitudinal wave speed and tensile strength of UHMW-PE fibres are higher than that of aramid fibres, contributing to improved ballistic performance. Carbon and glass fibres have high longitudinal wave speeds and tensile strengths; in the case of carbon fibre even exceeding those of UHMW-PE fibre [28], however their ballistic performance is poor in comparison. This can be related to the microstructure of the different fibre types. UHMW-PE and aramid fibres are microfibrillar and therefore under lateral strains induced by the impact their performance in the fibre direction is not significantly affected [28, 29]. Carbon fibre has an anisotropic microstructure, which behaves in a brittle manner under lateral strain, leading to failure by fibre crushing rather than redistributing the load in membrane tension. Similarly, glass fibres, although isotropic in microstructure, are also sensitive to compression failure under lateral strain. Carbon and glass fibres, therefore, experience localised fibre failure under transverse ballistic loads [30], so that any advantage of high tensile properties for membrane loading is nullified. 
The absence of areal density and projectile data for the aramid, glass and carbon fibre composites in [1] does not permit an evaluation of mass and space efficiency in terms of target areal density, as performed in section 4.1 for the metallic armours. Instead, a linear relationship is derived for each composite material, from which the mass and space efficiency are determined as follows:

$$
E_{m}=\frac{\left({ }^{A} D_{t} A_{p} / m_{p}\right)_{r e f}}{\left({ }^{A D_{t} A_{p}} / m_{p}\right)}=\frac{\left(A D_{t}\right)_{r e f}}{A D_{t}} \text { and } E_{s}=E_{m}\left(\frac{\rho}{\rho_{\text {ref }}}\right)
$$

Figure 10 and Figure 11 show the mass efficiency and space efficiency of the various composites, where UHMW-PE composite is used as the reference material.

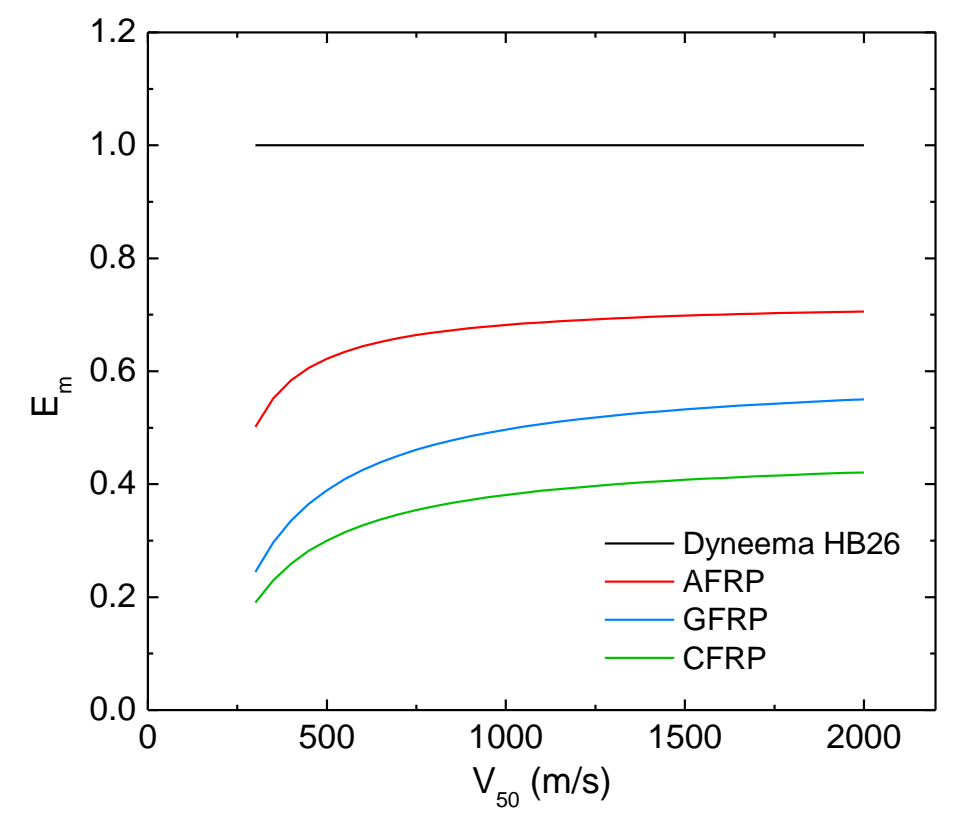

Figure 10. Mass efficiency of fibre-reinforced composites in terms of target ballistic limit. 


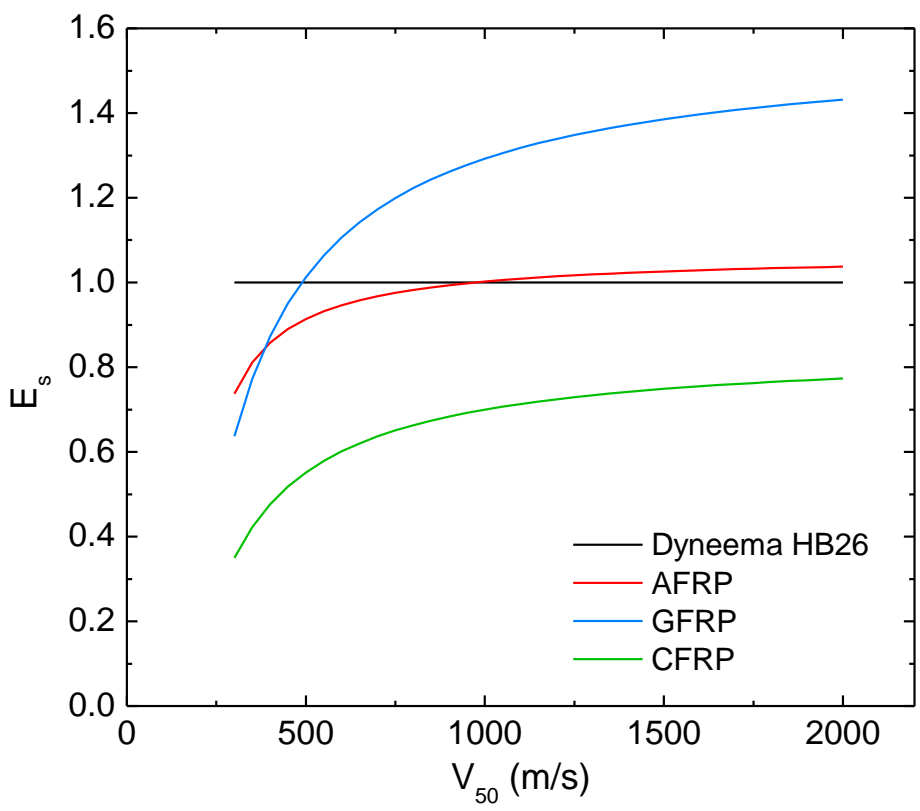

Figure 11. Space efficiency of fibre reinforced composites in terms of target ballistic limit.

The mass efficiency of UHMW-PE composite is found to be approximately $30 \%$ higher than AFRP, $50 \%$ higher than GFRP and 60\% higher than CFRP. The space efficiency of GFRP and AFRP are higher than that of UHMW-PE for $\mathrm{V}_{50}$ values greater than about $500 \mathrm{~m} / \mathrm{s}$ and $1000 \mathrm{~m} / \mathrm{s}$ respectively, with GFRP having the highest space efficiency of all four composites above a $V_{50}$ of around $500 \mathrm{~m} / \mathrm{s}$. The non-linear relationship between the mass and space efficiency of UHMW-PE and the three other composite materials is considered to be a result of the two-phase penetration mechanism discussed in section 4.1 (see Figure 5(b)). As identified in the previous section, UHMW-PE is most efficient in thin sections that are perforated in membrane tension. As such, the mass and space efficiency of UHMW-PE composite, in comparison with the other composite panels, is highest for thin sections, where target thickness and $\mathrm{V}_{50}$ are proportional. For panels sufficiently thick, with sufficiently high $\mathrm{V}_{50}$ to demonstrate a two-stage perforation process, the mass efficiency of the AFRP, GFRP and CFRP composites stabilise relative to the UHMW-PE composite.

\section{Conclusion}

An extensive experimental program was conducted to determine the ballistic limit of UHMW-PE composite against $12.7 \mathrm{~mm}$ and $20 \mathrm{~mm}$ fragment simulating projectiles (FSPs) for a wide range of 
thicknesses. The performance of UHMW-PE was compared to that of typical metallic armours, which were rolled homogenous armour steel, high hardness armour steel, and aluminium alloy Al 5059H131. Against FSPs, UHMW-PE composite was much more mass efficient than the metallic armours $\left(3.0<\mathrm{E}_{\mathrm{m}}<4.0\right)$ and less space efficient than both of the steel armours. Relative to RHA steel, the performance of UHMW-PE composite was more mass efficient against $20 \mathrm{~mm}$ FSPs than $12.7 \mathrm{~mm}$ FSPs due to sensitivity of the RHA to scaling effects. UHMW-PE composite was not found to be sensitive to projectile scaling.

The performance of UHMW-PE was also compared to aramid, glass, and carbon fibre-reinforced composites under fragment impact. UHMW-PE was found to be the most mass efficient of the composites considered, although it was less space efficient than the glass and aramid fibre-reinforced composites for target ballistic limits above $1000 \mathrm{~m} / \mathrm{s}$.

The effectiveness of UHMW-PE, in comparison with the metallic and composite armours considered, was found to be significantly affected by the mechanism under which penetration occurred. For thin panels, which are subject to perforation by membrane tension, the efficiency was markedly higher than for thicker panels which are perforated in a two-stage process including initial shear plugging followed by membrane tension. Although providing highly mass efficient fragment protection in both penetration modes, the ballistic mass efficiency is maximised when the material response is not localised.

\section{Acknowledgement}

The work reported herein was funded by the Defence Science and Technology Organisation (DSTO) under the Land Vehicle Survivability Science and Technology Capability (STC). The authors would also like to acknowledge the support of both RMIT University and the Defence Materials Technology Centre (DMTC) in providing a PhD scholarship to the lead author. The DMTC was established and is supported by the Australian Government's Defence Future Capability Technology Centre (DFCTC) initiative. 


\section{Reference}

1. Cunniff PM (1999) Dimensionless parameters for optimization of textile based body armor systems. In: Reinecke W (ed) 18th International Symposium and Ballistics. Technomic Publishing Co, San Antonio, pp 1303-1310

2. Lee BL, Song JW, Ward JE (1994) Failure of Spectra Polyethylene Fiber-Reinforced Composites under Ballistic Impact Loading. Journal of Composite Materials 28:1202-1226. doi: $10.1177 / 002199839402801302$

3. Iremonger M (1999) Polyethylene composites for protection against high velocity small arms bullets. 18th International Symposium on Ballistics. Technomic Publishing Co, San Antonio, pp 946-953

4. Morye S, Hine P, Duckett R, Carr D, Ward I. (1999) A comparison of the properties of hot compacted gel-spun polyethylene fibre composites with conventional gel-spun polyethylene fibre composites. Composites Part A 30:649-660. doi: 10.1016/S1359-835X(98)00175-4

5. Lässig T, Nguyen L, May M, Riedel W, Heisserer U, Van der Werff H, Hiermaier S. (2015) A non-linear orthotropic hydrocode model for ultra-high molecular weight polyethylene in impact simulations. International Journal of Impact Engineering 75:110-122. doi: 10.1016/j.ijimpeng.2014.07.004

6. Greenhalgh ES, Bloodworth VM, Iannucci L, Pope D (2013) Fractographic observations on Dyneema ${ }^{\circledR}$ composites under ballistic impact. Composites Part A: Applied Science and Manufacturing 44:51-62. doi: 10.1016/j.compositesa.2012.08.012

7. Nguyen LH, Ryan S, Cimpoeru SJ, Mouritz AP, Orifici AC. (2015) The effect of target thickness on the ballistic performance of ultra high molecular weight polyethylene composite. International Journal of Impact Engineering 75:174-183. doi: 10.1016/j.ijimpeng.2014.07.008 
8. Phoenix SL, Porwal PK (2003) A new membrane model for the ballistic impact response and V50 performance of multi-ply fibrous systems. International Journal of Solids Structures 40:67236765. doi: 10.1016/S0020-7683(03)00329-9

9. Hohler V, Stilp AJ, Weber K (1995) Hypervelocity penetration of tungsten sinter-alloy rods into aluminum. International Journal of Impact Engineering 17:409-418. doi: 10.1016/0734743X(95)99866-P

10. Madhu V, Ramanjaneyulu K, Balakrishna Bhat T, Gupta NK (2006) An experimental study of penetration resistance of ceramic armour subjected to projectile impact. International Journal of Impact Engineering 32:337-350. doi: 10.1016/j.ijimpeng.2005.03.004

11. Savio SG, Ramanjaneyulu K, Madhu V, Bhat TB (2011) An experimental study on ballistic performance of boron carbide tiles. International Journal of Impact Engineering 38:535-541. doi: 10.1016/j.ijimpeng.2011.01.006

12. Department of Defense (2006) Projectile, calibre .22, .30, .50, and $20 \mathrm{~mm}$ fragment simulating. MIL-DTL-46593B

13. Department of Defense (1997) V50 Ballistic Test for Armor. MIL-STD-662F

14. Department of Defense (2008) Armor plates, steel, wrought, high-hardness. MIL-DTL-46100E

15. Department of Defense (1990) Armour plate, steel, wrought, homogenous. MIL-A-12560H

16. Gooch W, Showalter D, Burkins M (2007) Ballistic Testing of Australian Bisalloy Steel for Armor Applications. In: Galvez F, Sanchez-Galvez V (eds) 23rd International Symposium on Ballistics. Tarragona, pp 1181-1188

17. Jones TL, Delorme RD, Burkins MS, Gooch WA (2007) Ballistic performance of magnesium alloy AZ31B. In: Galvez F, Sanchez-Galvez V (eds) 23rd International Symposium on Ballistics. Tarragona, pp 989-995 
18. Thorn V (2009) The ballistic performance of various armour steels against fragment simulating projectiles. DSTO-TR-2316.

19. Showalter DD, Placzankis BE, Burkins MS (2007) Ballistic performance testing of aluminum alloy 5059-H131 and 5059-H136 for armor applications. ARL-TR-4427.

20. Mascianica F (1981) Ballistic Technology of Lightweight Armor. AMMRC TR-8120.

21. Cunniff P (1992) An analysis of the system effects in woven fabrics under ballistic impact. Textile Research Journal 62:495-509. doi: 10.1177/004051759206200902

22. Woodward RL (1978) The penetration of metal targets which fail by adiabatic shear plugging. International Journal of Mechanical Sciences 20:599-607. doi: 10.1016/0020-7403(78)90018-8

23. Dikshit SN, Kutumbarao VV, Sundararajan G (1995) The influence of plate hardness on the ballistic penetration of thick steel plates. International Journal of Impact Engineering 16:293-320. doi: 10.1016/0734-743X(94)00041-T

24. Børvik T, Leinum JR, Solberg JK, Hopperstad OS, Langseth M. (2001) Observations on shear plug formation in Weldox $460 \mathrm{E}$ steel plates impacted by blunt-nosed projectiles. International Journal of Impact Engineering 25:553-572. doi: 10.1016/S0734-743X(00)00069-5

25. Magness LS, Farrand TG (1990) Deformation Behavior and its relationship to the penetration performance of high density KE penetrator materials. In: Assistant Secretary of the Army (ed) 17th Army Science Conference. Department of the Army, Durham, pp 465-479

26. Anderson CE, Mullin SA, Kuhlman CJ (1993) Computer simulation of strain-rate effects in replica scale model penetration experiments. International Journal of Impact Engineering 13:3552. doi: 10.1016/0734-743X(93)90107-I

27. Anderson CE, Mullin SA, Piekutowski AJ, Blaylock NW, Poormon KL. (1996) Scale model experiments with ceramic laminate targets. International Journal of Impact Engineering 18:1-22. doi: 10.1016/0734-743X(95)00026-1 
28. Cunniff PM, Auerbach MA, Vetter E, Sikkema DJ (2002) High performance "M5" fiber for ballistics/structural composites. 23rd Army Science Conference

29. Cheng M, Chen W, Weerasooriya $\mathrm{T}$ (2004) Experimental investigation of the transverse mechanical properties of a single Kevlar ${ }^{\circledR}$ KM2 fiber. International Journal of Solids and Structures 41:6215-6232. doi: 10.1016/j.ijsolstr.2004.05.016

30. Woodward RL, Egglestone GT, Baxter BJ, Challis K (1994) Resistance to penetration and compression of fibre-reinforced composite materials. Composites Engineering 4:329-341. doi: $10.1016 / 0961-9526(94) 90083-3$ 


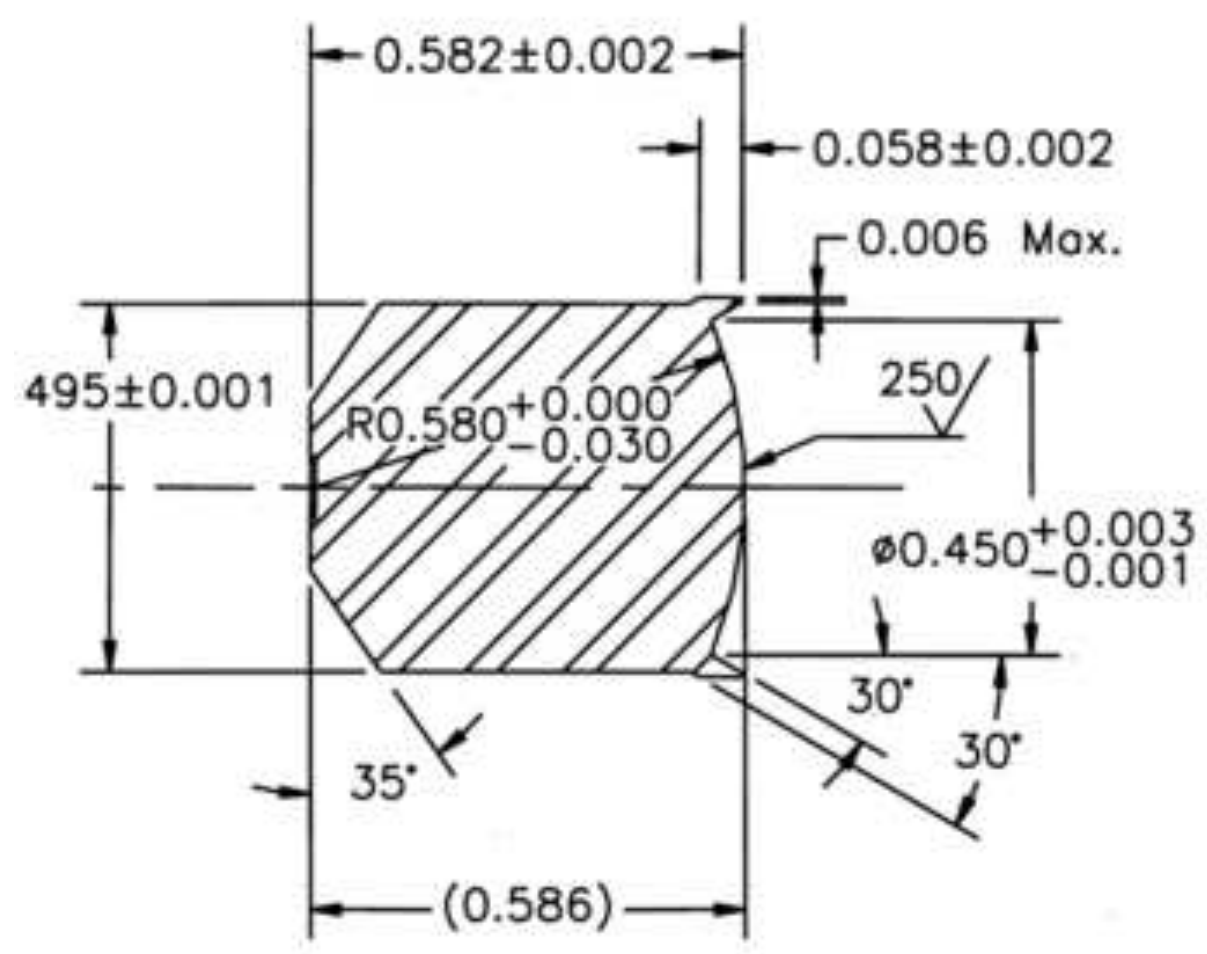

$12.7 \mathrm{~mm}$ FSP

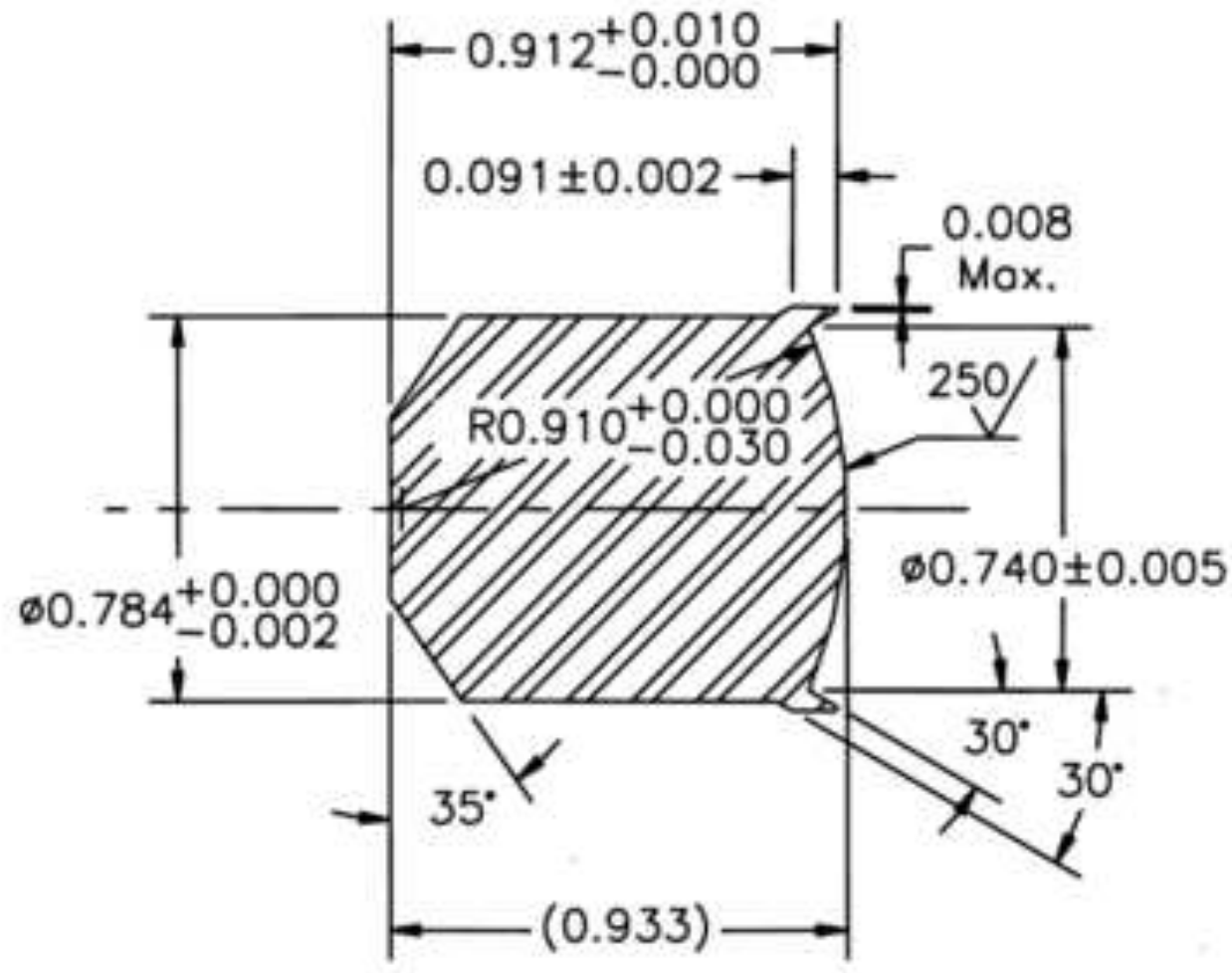

$20 \mathrm{~mm}$ FSP 


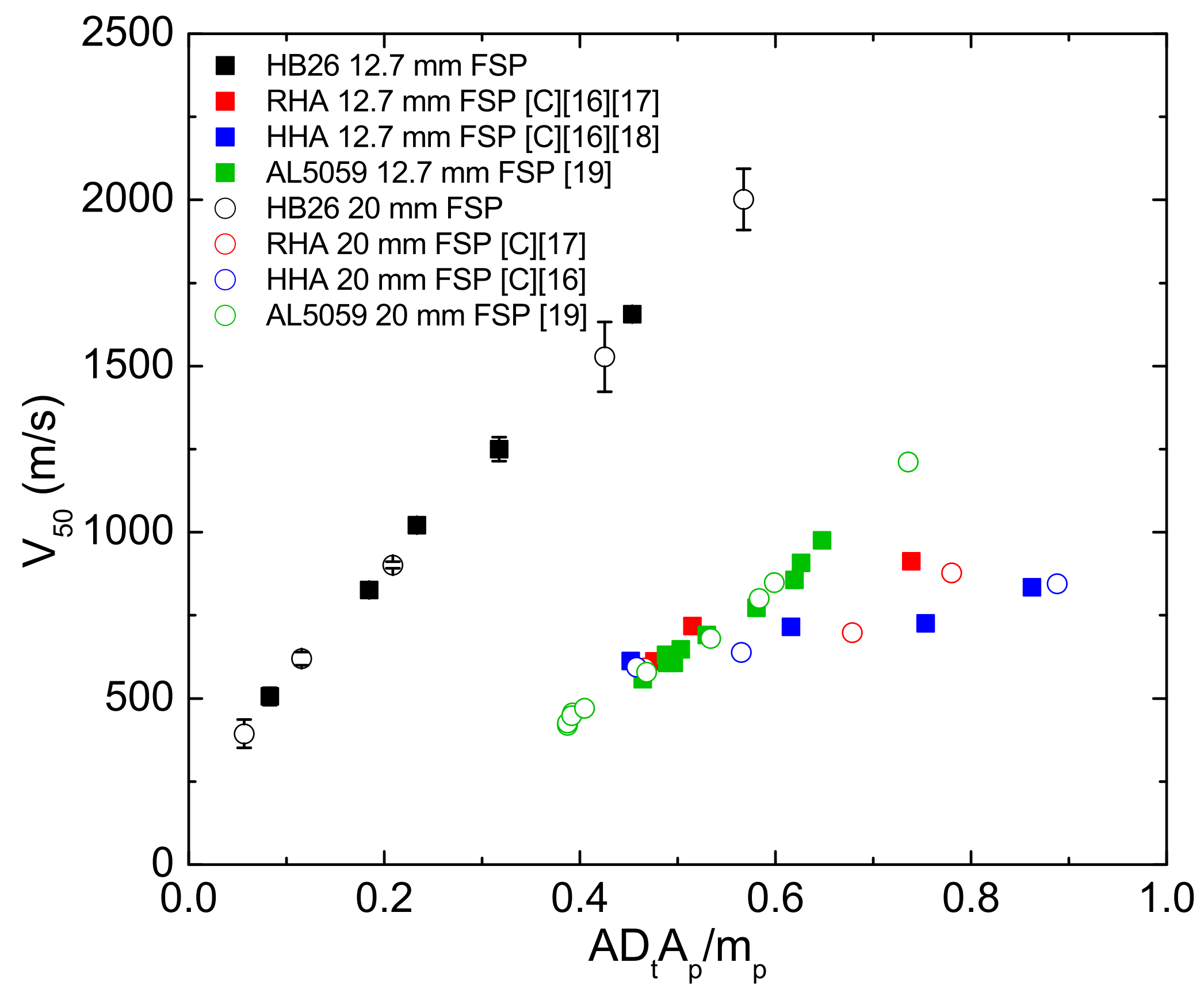


Click here to download Figure: figure_3.eps

(a)
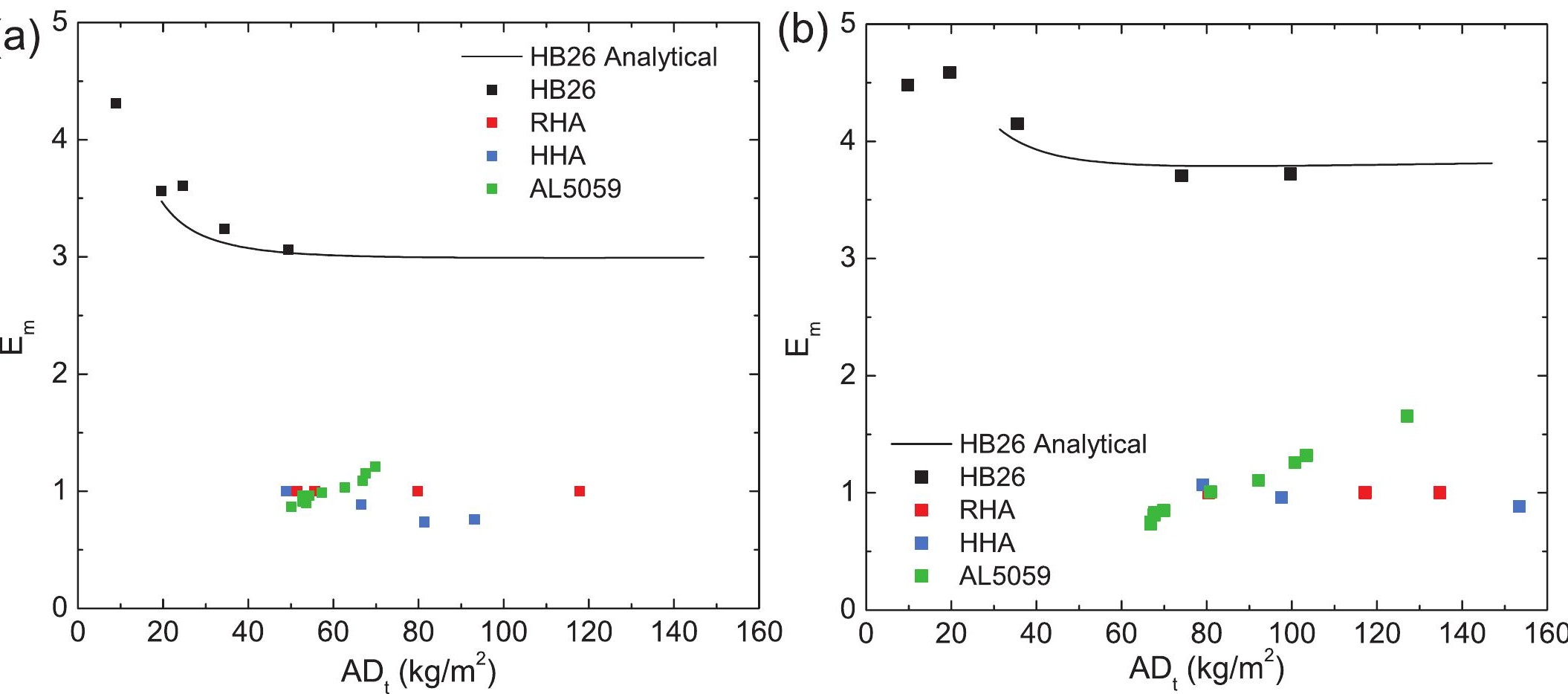


\section{Figure 4}

Click here to download Figure: figure_4.eps

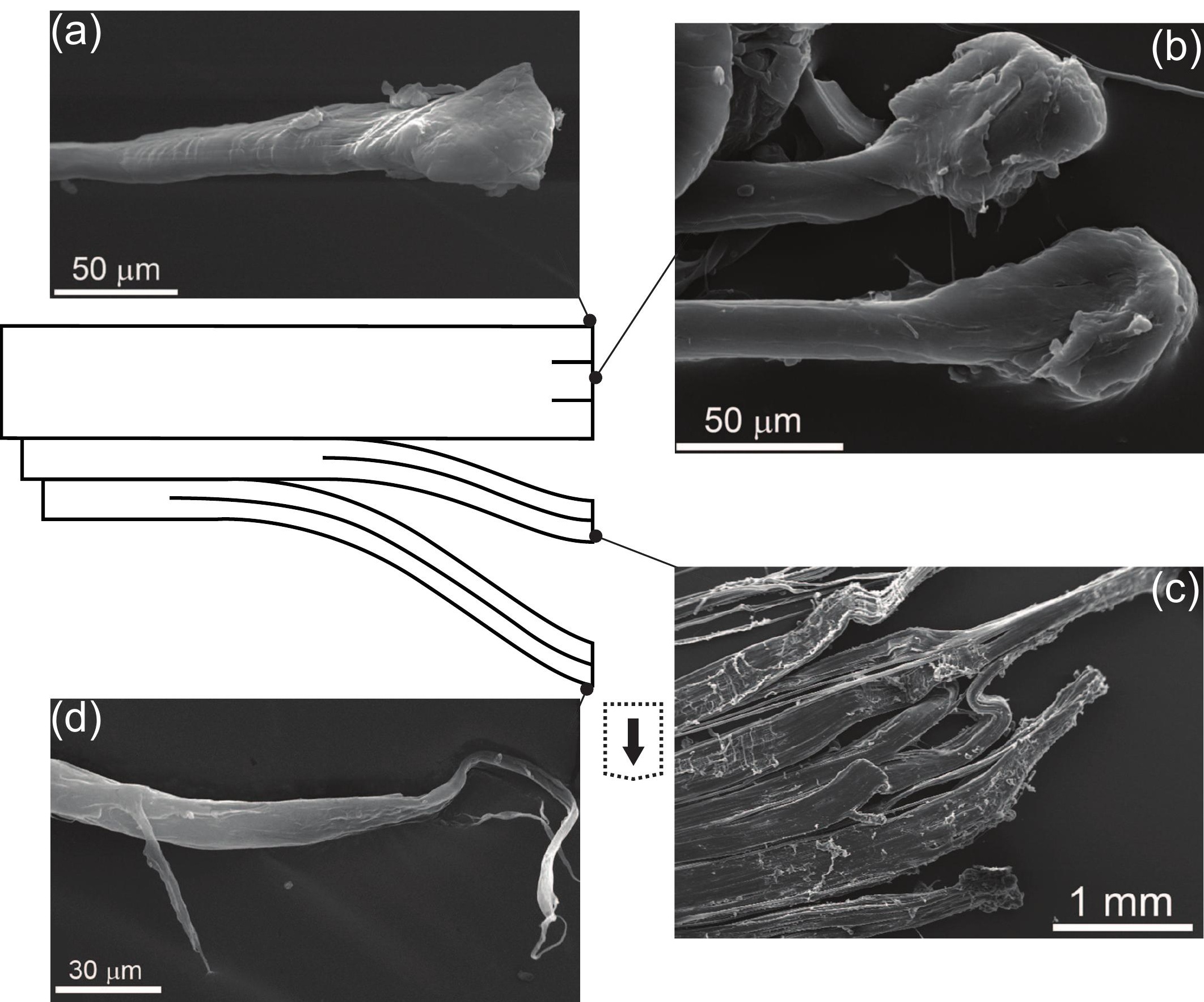




\section{Figure 5}

Click here to download Figure: figure_5.eps

$(a$

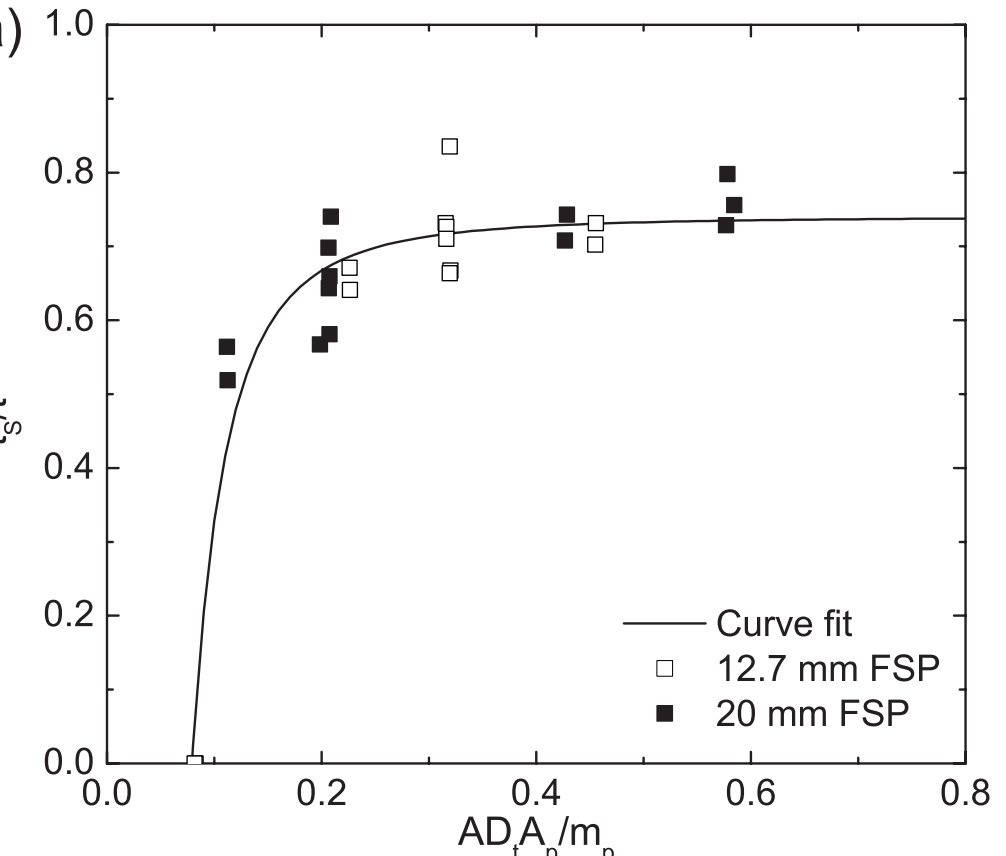

(b)

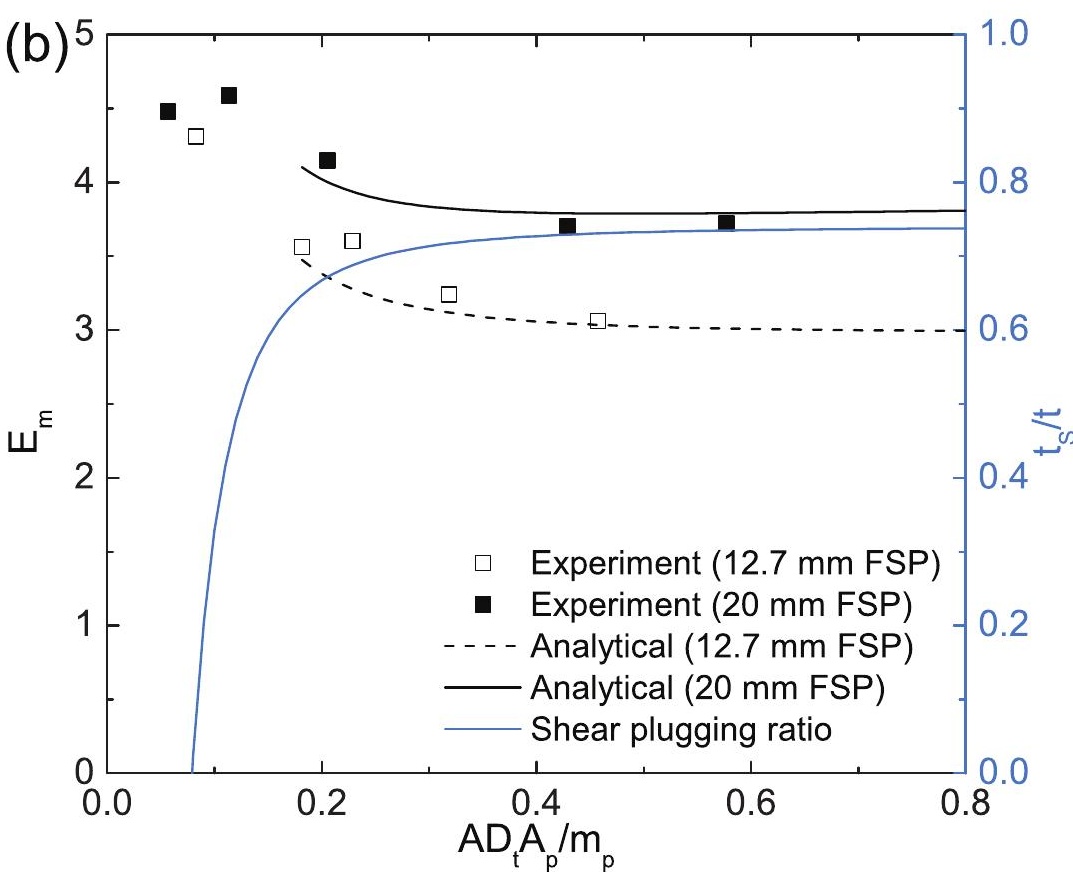



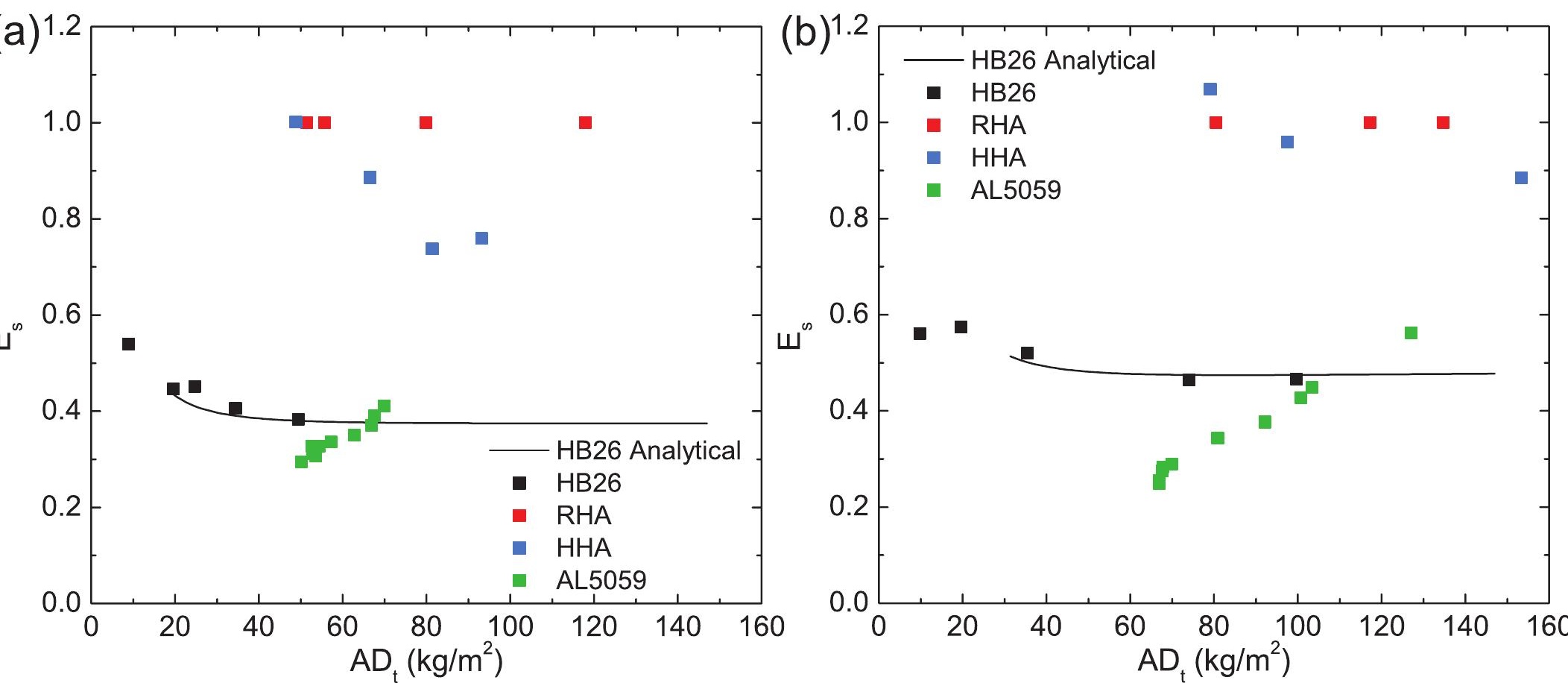
(a)

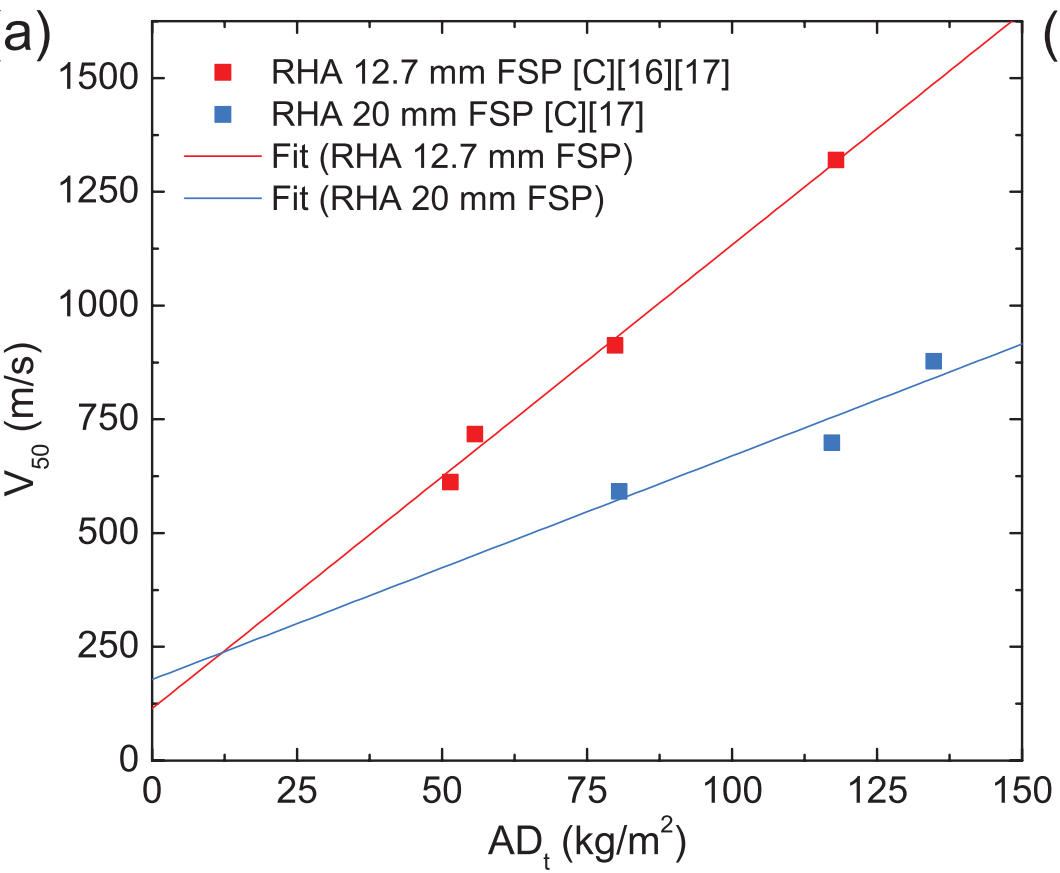

$$
\begin{gathered}
\text { (c) } \\
1 \\
1 \\
1 \\
\text { 离 } \\
\underbrace{0} \\
>^{0}
\end{gathered}
$$

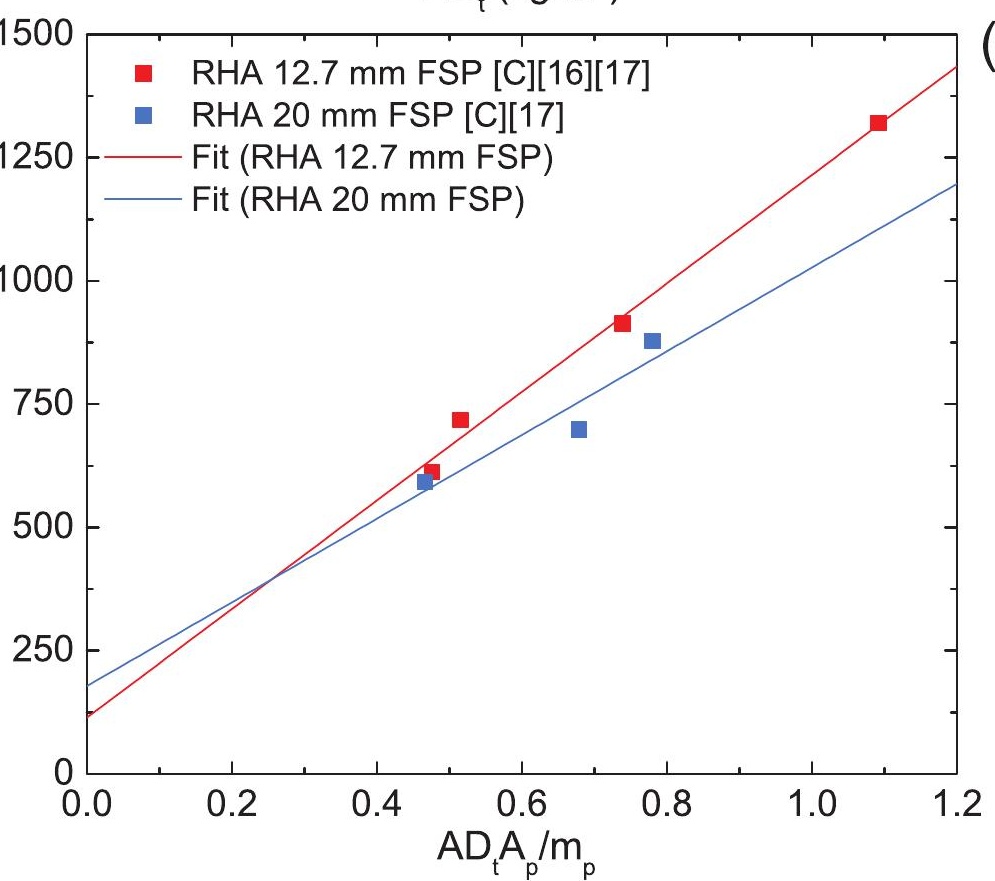

(b) 2500
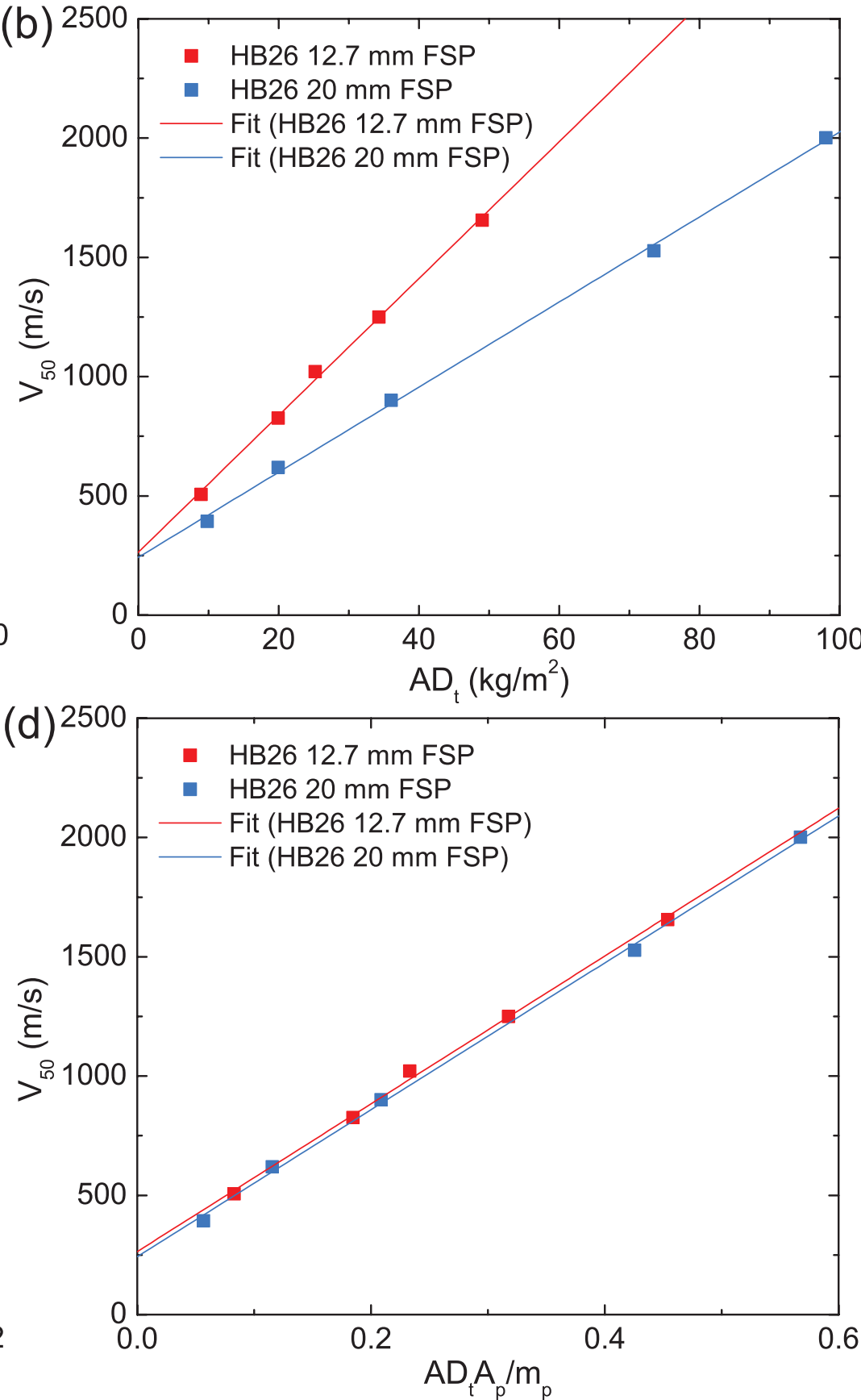
(a) 1

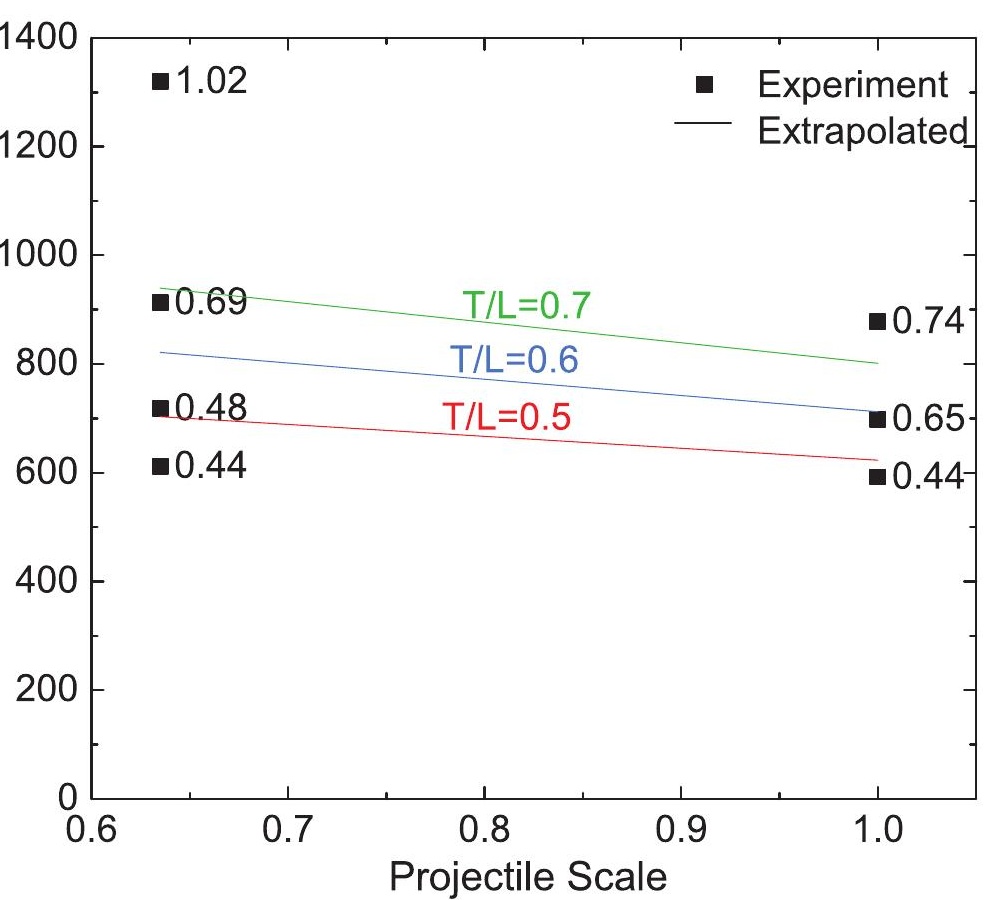

(b)

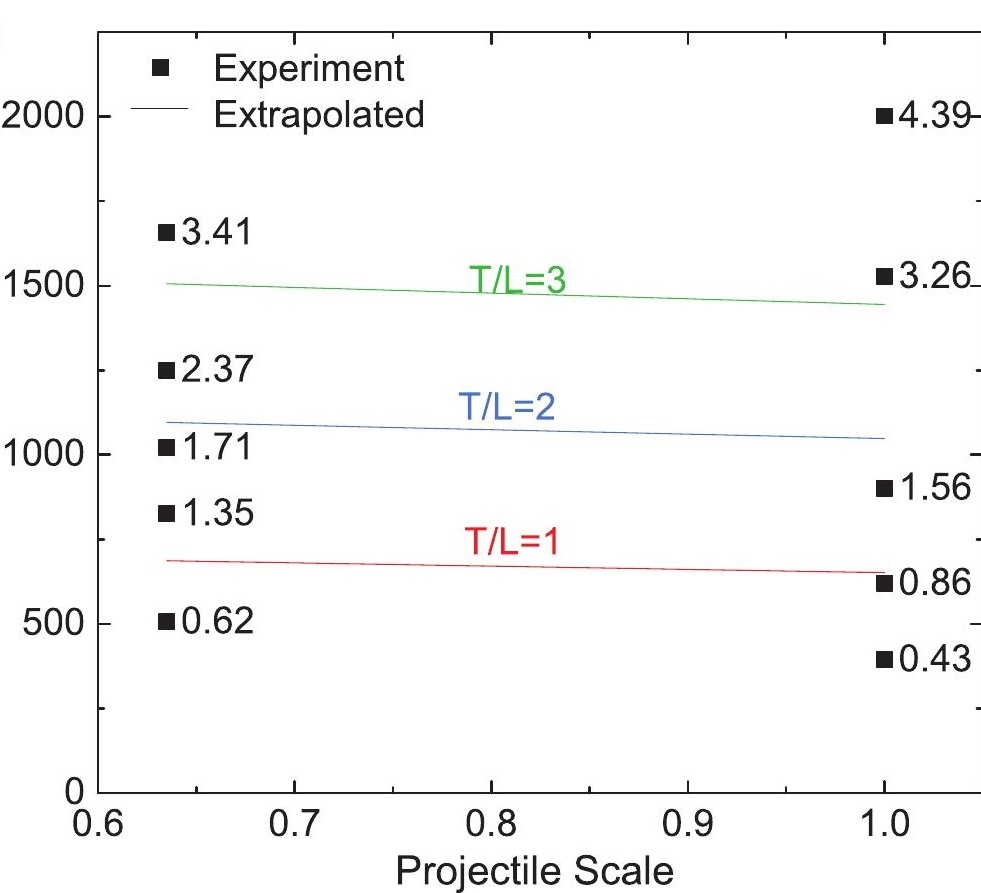




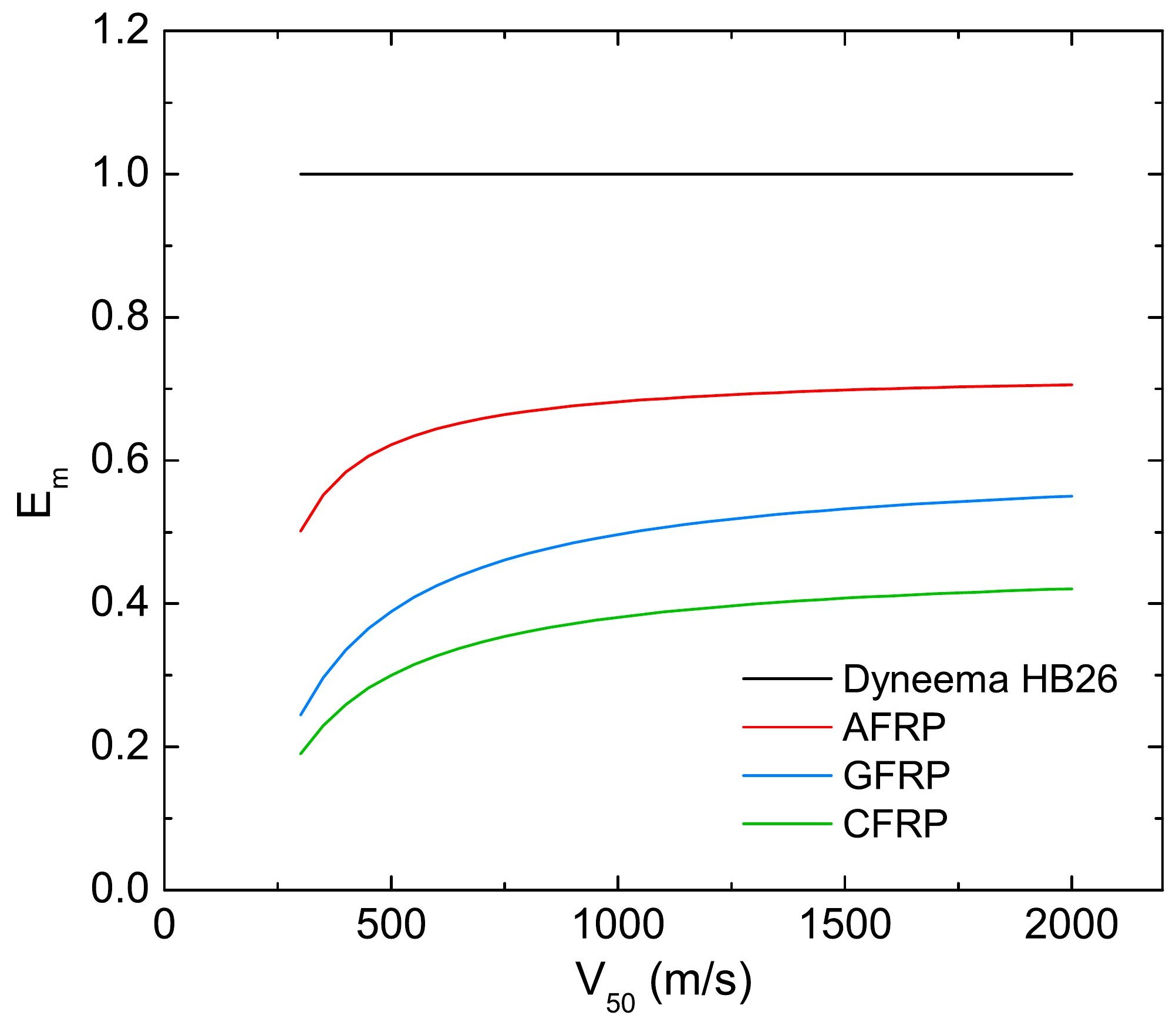




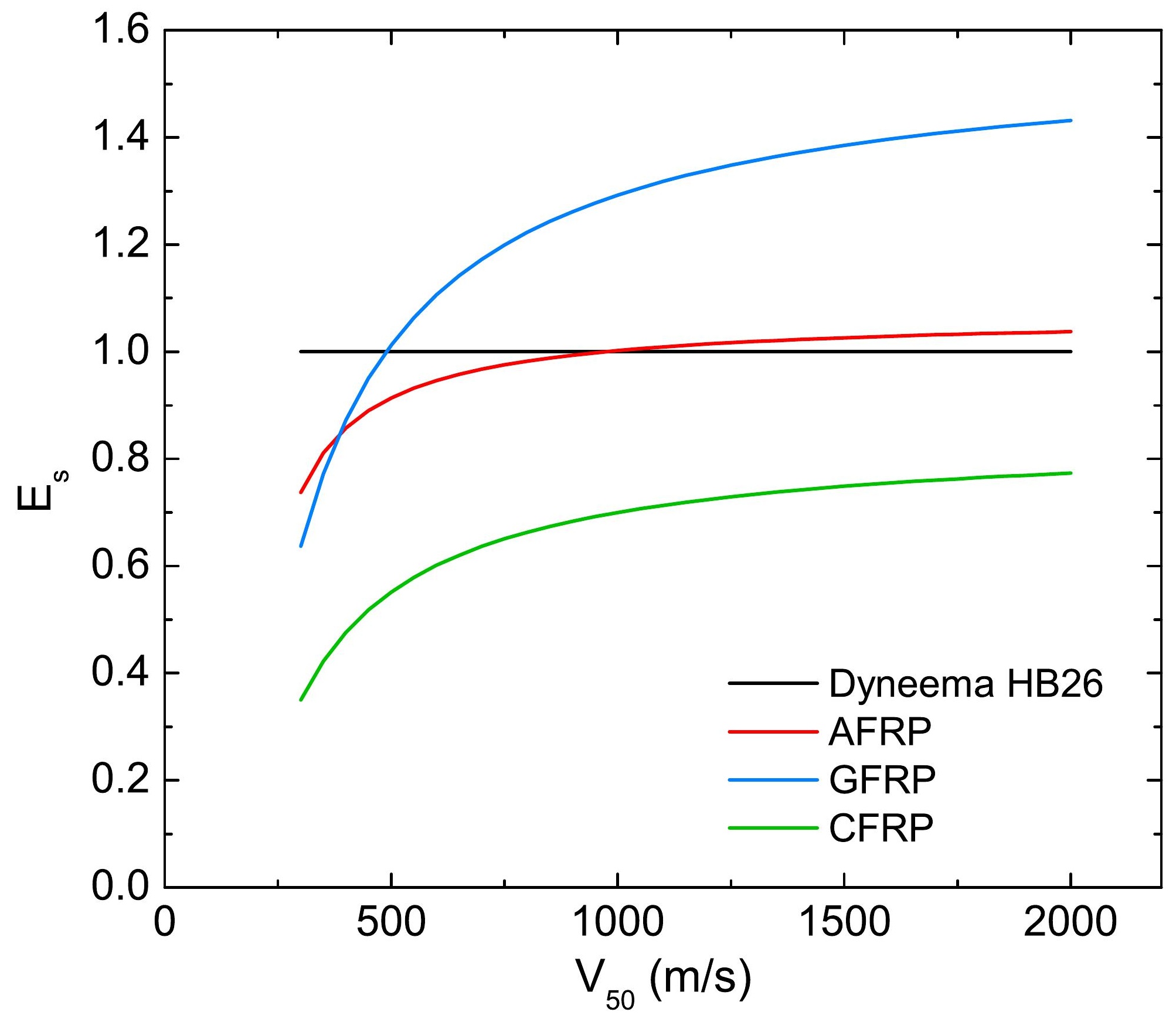




\section{Click here to download Table: table_1.xlsx}

\begin{tabular}{|c|c|c|c|c|}
\hline Material & Thickness (mm) & Projectile & $\mathrm{V}_{50}(\mathrm{~m} / \mathrm{s})$ & $\sigma(\mathrm{m} / \mathrm{s})$ \\
\hline Dyneema® HB26 & 9.1 & $12.7 \mathrm{~mm}$ FSP & 506 & 26.4 \\
\hline Dyneema ${ }^{\circledR}$ HB26 & 20 & $12.7 \mathrm{~mm}$ FSP & 825.8 & 17.2 \\
\hline Dyneema® HB26 & 25.2 & $12.7 \mathrm{~mm}$ FSP & 1021.4 & 8.5 \\
\hline Dyneema ${ }^{\circledR}$ HB26 & 35.1 & $12.7 \mathrm{~mm}$ FSP & 1250.3 & 36.1 \\
\hline Dyneema® HB26 & 50.4 & $12.7 \mathrm{~mm}$ FSP & $1656.5^{*}$ & 16.3 \\
\hline Dyneema ${ }^{\circledR}$ HB26 & 10 & $20 \mathrm{~mm}$ FSP & 393.9 & 43 \\
\hline Dyneema ${ }^{\circledR}$ HB26 & 20 & $20 \mathrm{~mm}$ FSP & 620.1 & 19.6 \\
\hline Dyneema® HB26 & 36.2 & $20 \mathrm{~mm}$ FSP & 901.4 & 9.8 \\
\hline Dyneema® HB26 & 75.6 & $20 \mathrm{~mm}$ FSP & 1527.6 & 104.6 \\
\hline Dyneema® HB26 & 101.7 & $20 \mathrm{~mm}$ FSP & 2001.8 & 91.8 \\
\hline RHA steel & 6.6 & $12.7 \mathrm{~mm}$ FSP & 612.1 & 8.5 \\
\hline RHA steel & 15.1 & $12.7 \mathrm{~mm}$ FSP & 1319.9 & 14.3 \\
\hline RHA steel & 10.3 & $20 \mathrm{~mm}$ FSP & 591.9 & 18.5 \\
\hline RHA steel & 15 & $20 \mathrm{~mm}$ FSP & 698.4 & 17.4 \\
\hline HHA steel & 6.2 & $12.7 \mathrm{~mm}$ FSP & 612.5 & 7.8 \\
\hline HHA steel & 10.1 & $20 \mathrm{~mm}$ FSP & 593.8 & 10.9 \\
\hline HHA steel & 12.5 & $20 \mathrm{~mm}$ FSP & 638 & 16.8 \\
\hline
\end{tabular}

